Joan B. López

\title{
Emili Junyent i Sànchez: algunes notes biogràfiques... des de la proximitat
}

\section{Emili Junyent i Sànchez: some biographical comments... from someone close to him}

\section{A tall d'introducció}

Vaig conèixer l'Emili l'any 1982 quan endegava la meva carrera i ell impartia classes a l'Estudi General de Lleida, llavors encara una delegació de la Universitat de Barcelona. Amb ell i l'Arturo Pérez també vaig tenir el meu primer contacte amb l'arqueologia en les excavacions que es duien a terme als soterranis de la Paeria de Lleida aquell mateix any 1982.

Des d'aquell moment, aquest contacte només es va interrompre parcialment durant els anys $1986 \mathrm{i}$ 1987 perquè el pla d'estudis de l'època ens obligava a realitzar els dos darrers anys d'especialitat a Barcelona. Jo volia, però, continuar la meva vinculació amb Lleida i, abans de marxar, li vaig demanar que dirigís la meva tesi de llicenciatura. Com que tampoc sabia encara massa què fer, ell em va suggerir introduir-me en el món de la informàtica aplicada a l'arqueologia. No era un consell innocent. A mitjan anys vuitanta començava a bullir a casa nostra el tema de la informatització dels sistemes de registre (excavació subaquàtica del vaixell Culib $I V$, treballs del TED'A a Tarragona...) i calia estar atents — com sempre feia- a qualsevol novetat que pogués produir-se en el camp de la renovació metodològica de l'arqueologia.
D'aquesta manera, em va escriure una carta de recomanació per a Michel Py, Michel Bats i Jean-Luc Fiches, directors del projecte que s'havia endegat l'any 1983 al jaciment de Lattes (Hérault, França) i que preveia entre els seus objectius la informatització integral del registre. Hi vaig anar l'any 1985 i l'any 1987, just acabada la carrera, en Michel Py, que havia restat com a únic director del projecte, em va integrar dins de l'equip de direcció. Hi vaig romandre fins l'any 2006, i vaig "importar" cap a casa nostra, principalment als Vilars d'Arbeca, però també a l'illa d'en Reixac (1987-1992), tota l'experiència i els coneixements metodològics adquirits, i vaig gaudir del mestratge d'en Michel, l'altra persona que també ha estat decisiva en la meva formació. Aquesta és, però, una altra història.

L'any 1989 presentava així a l’Estudi General de Lleida la meva tesi de llicenciatura: Aplicacions de la microinformàtica en la recerca protohistòrica, dirigida per l'Emili, i aquell mateix any aconseguia per primera vegada un contracte de professor associat a temps parcial per substituir-lo en la docència d'una assignatura que ell alliberava en la seva condició de president de la Junta de Personal Acadèmic. Per una altra banda, l'any 1988 m'havia incorporat, juntament amb l'Ángel Lafuente, a l'equip dels Vilars que llavors dirigien ell i l'Ignasi Garcés. 
Amb el seu aval i suport, aquell contracte va generar l'any 1992 un concurs de professor ajudant a temps complet, que vaig poder guanyar i em va permetre cursar amb tranquil.litat el programa de doctorat i redactar, també sota la seva direcció, la meva tesi doctoral, que vaig presentar l'any 2000.

Amb tanta lentitud, vaig aconseguir crispar-lo alguna vegada, però he de dir en el meu descàrrec que, cansat de la informàtica, havia decidit amb el seu vistiplau canviar completament de tema i centrar-me en quelcom més vinculat al terreny, com és l'arquitectura i l'urbanisme protohistòrics a la plana occidental catalana. D'altra banda, el meu sou de professor ajudant m'obligava a cercar altres fonts de finançament paral-leles per poder subsistir. Finalment, l'any 2002 la nova Universitat de Lleida, creada l'any 1994, va convocar (després de no poques negociacions i pressions per part del col-lectiu de professors associats i davant la imminent posada en funcionament de la LOU) diferents places de promoció, entre les quals n'hi havia una de professor titular de prehistòria, que vaig poder assolir en l'oposició corresponent, en què l'Emili era el president del tribunal.

La confiança que va dipositar en mi en aquells inicis va ser decisiva perquè, malgrat la precarietat de les condicions de treball, em mantingués ferm en continuar la meva carrera acadèmica, i és quelcom que no sé si mai podré agrair-li suficientment. Els trenta-cinc anys viscuts a la seva vora, compartint despatx, docència i recerca, han generat que la relació mestre-alumne esdevingués ben aviat una relació entre iguals, però sobretot una relació d'amistat i afecte que transcendeix l'àmbit acadèmic i professional.

Explico tot això perquè no sé si la semblança sobre la seva trajectòria, que ara presento, serà tan objectiva com hauria de ser i demano disculpes al lector/a d'entrada. També les faig extensives a tu, Emili, per si hi ha comentaris que no em calia fer públics.

\section{Apunts biogràfics}

Neix a Vilafranca del Penedès (Alt Penedès) l'1 de juny de 1946 i està casat des de l'any 1971 amb Núria Torrades i Carbó amb la qual són pares de dos fills: en Fidel i en Vladimir. La seva residència familiar sempre ha estat Barcelona, però crec que durant la seva etapa docent va passar molt més temps a Lleida, on durant molts anys compartia pis amb l'Arturo Pérez, col-legues a la Universitat i amics entranyables.

Té, però, des que jo el conec, un altre racó que l'enamora i constitueix el seu "refugi", lloc de repòs, d'esbarjo i "càrrega de bateries": la casa d'Alaior a Menorca. Durant la seva vida activa, mai va poder gaudir-la tant com hauria desitjat. Gran amant del cinema i l'art i lector incansable, una de les seves altres grans passions és la mar i la pesca submarina (en apnea, és clar, i a l'espera - sempre matisa-) (figura 1); esportivament, uns sols colors: el Barça.

Ideològicament el seu pensament d'esquerres i arrel marxista és conegut per tothom. El seu esperit crític, sovint dur i incisiu, però mai insultant, li ha fet guanyar amics i enemics; no obstant això, vagi on vagi és respectat pel seu rigor, honestedat i coherència intel.lectual i humana. En conseqüència,

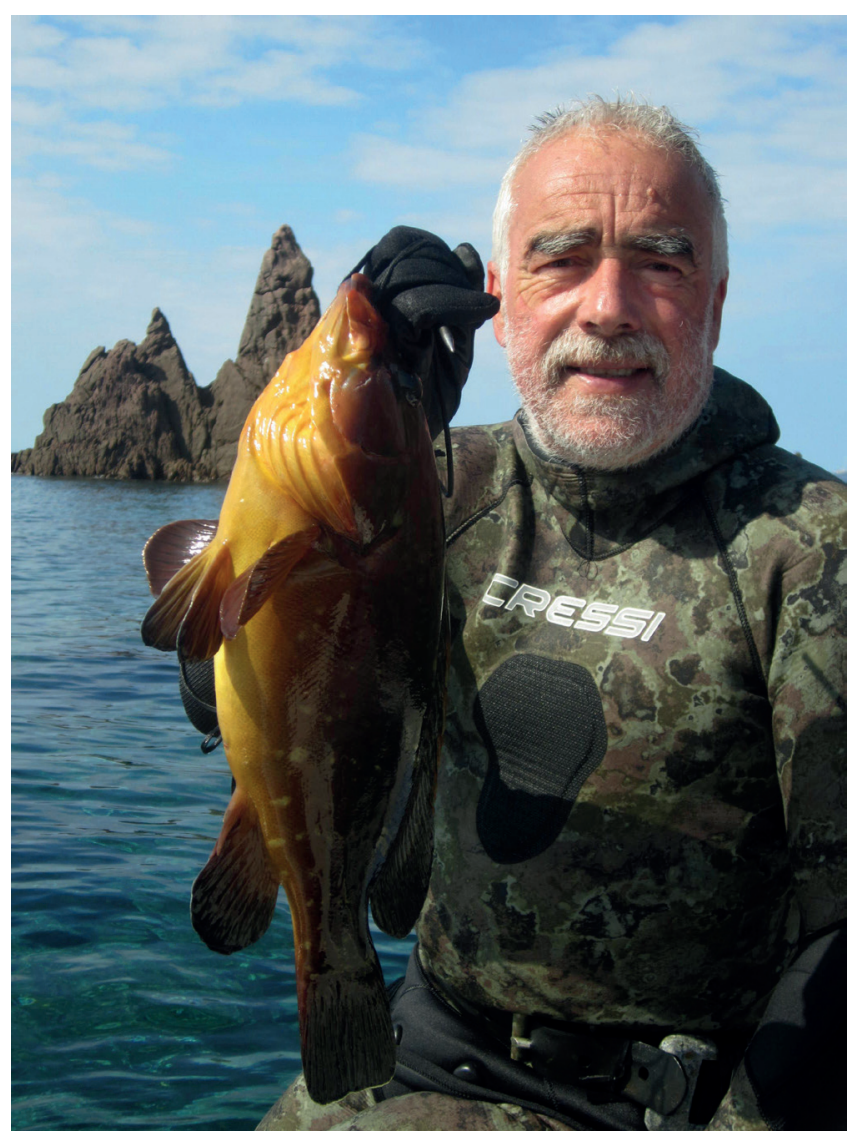

Figura 1. L’Emili amb un anfós capturat en aigües de Menorca l'any 2014.

les seves conviccions eticopolítiques han marcat la seva vida universitària i li agrada dir que de poques coses se sent tan orgullós com d'haver participat a la Caputxinada i ser membre del Sindicat Democràtic d'Estudiants de la Universitat de Barcelona, l'SDEUB (1966); haver-se implicat a fons, com a responsable de la Facultat de Geografia i Història de l'Estudi General, en la defensa de la llibertat d'expressió i de l'estudiant Cèsar Alegre processat a causa de l'affaire de La Higiènica que sacsejà la ciutat de Lleida (1980) (Junyent 2017); o, sent degà de la Facultat de Lletres, de la declaració com a persona non grata del president del govern espanyol José María Aznar, com a protesta contra la Guerra d'Iraq (2003).

\section{Trajectòria acadèmica i docent}

Es va formar a la Universitat de Barcelona, on va obtenir el títol de llicenciatura en Filosofia i Lletres, secció Història Antiga, l'any 1970 i el títol de grau l'any següent: 1971. Entre 1970 i 1974, Joan Maluquer de Motes li aconsegueix el seu primer contracte universitari com a professor ajudant a la UB on imparteix puntualment l'assignatura de cultura ibèrica i tot seguit (1974) l'envia a Lleida com a funcionari interí del cos facultatiu de museus, a l'espera de les oposicions corresponents; a Lleida aquesta institució no va arribar mai a concretar-se. Aquesta etapa de la seva vida l'ha explicat ell mateix amb detall (Junyent 2013: 273-279), per la qual cosa m'abstindré d'estendrem'hi gaire. Recollint el seu propi relat, assenyalaria 
que són els anys en què, amb molt poques obligacions docents malgrat la plaça d'ajudant, aprofita per redactar, dirigida per Joan Maluquer, la seva tesi doctoral: La filiación cultural del horizonte ibérico antiguo en tierras catalanas, un treball en molts aspectes encara vigent, però que no va arribar a publicar-se. No n'he sabut mai la raó exacta, potser el desacord del mateix Maluquer amb algunes de les conclusions, però sé que l'Emili ha lamentat sempre no haver-ho fet. La va defensar l'any 1976 a la Universitat de Barcelona i va ser guardonada amb el premi extraordinari de doctorat l'any següent (1977). ${ }^{1}$

Faig aquí un incís per insistir en la influència professional i fins $\mathrm{i}$ tot humana que la figura de Joan Maluquer ha tingut en la seva vida. Ell mateix ho ha reconegut (Junyent 1991; 2013; 2017) i ha fet pública la seva admiració vers ell en qualitat de mestre, investigador i acadèmic, a l'igual que ha manifestat el seu desacord amb algunes de les seves actuacions en aquests camps. Però, per damunt de tot, ha prevalgut un sentiment de gratitud immensa vers la persona. No hi ha dubte que la relació personal entre ambdós transcendí l'àmbit professional i que la pròpia família n'era conscient perquè, pocs anys després de la seva mort l'any 1988, la seva esposa Maria Bernet Ribera i fills li van demanar que actués com a mediador per poder llegar el fons bibliogràfic de l'insigne investigador a la Universitat de Lleida. L'acte s'oficialitzà el 22 de novembre del 2012.

En qualsevol cas i reprenent el fil descriptiu de la seva trajectòria acadèmica, l'any 1975, davant del futur incert de la carrera museística i atret per la vida universitària decideix emancipar-se del seu valedor i s'incorpora com a professor a temps parcial a l'Estudi General de Lleida, que aquell any havia passat a dependre una altra vegada de la Universitat de Barcelona. ${ }^{2}$ Larribada de l'Emili es produí un any després del trasllat (1974) dels estudis de Dret i Filosofia i Lletres a l'edifici del convent del Roser al carrer Cavallers, la qual cosa representava una millora significativa de les condicions de l'ensenyament ja que, per primera vegada, l'Estudi General va poder disposar d'un espai de biblioteca i despatxos per al professorat (Bellet 2010: 113). L'any 1978 es va incorporar l'Arturo Pérez i tots dos van romandre com a únics professors de les àrees d'Arqueologia, Prehistòria i Història Antiga fins l'any 1987, quan

1. Paradoxalment, la proposta per optar al reconeixement no la va fer el departament sinó l'antropòleg Claudi Esteva Fabregat.

2. Lleida havia començat a recuperar els seus estudis universitaris l'any 1966 impartint els ensenyaments del títol de Graduat Social de l'Escola Social de Barcelona. Posteriorment, l'any 1968, l'Estudi General de Lleida és reconegut oficialment com a centre d'estudis superior, dependent d'una fundació conjunta de la Paeria i la Diputació de Lleida i adscrit a la Universitat de Barcelona (UB); aquell any comencen a impartirse els estudis de dret. El curs 1971-1972, després d'un primer assaig l'any 1970 com a extensió universitària de la Facultat de Filosofia i Lletres de la UB, aquests estudis es deleguen a la Universitat Autònoma de Barcelona (UAB) i finalment l'any 1975 passen a dependre novament de la UB (Moreno 2006: 15). Durant aquesta primera etapa (1971-1974), les classes s'impartien a l'Antic Hospital de Santa Maria i va ser José Luis Maya (1949-2001 †) el primer professor de prehistòria que tingué l'Estudi General. arribà a l’Estudi General la Núria Rafel, que des de l'any 1983 treballava a Lleida com a arqueòloga dels Serveis Territorials del Departament de Cultura de la Generalitat de Catalunya.

Durant aquests anys inicials, tot i gaudir de contractes a temps complet, la situació laboral d'ambdós professors no deixava de resultar precària i hagueren d'esperar fins inicis dels anys vuitanta, quan la Universitat de Barcelona, sota el mandat del rector Antoni Badia Margarit, endegà una política d'ampliació i consolidació de les places de professorat (Barrull 2009: 51) i d'aquesta manera l'Arturo Pérez assolí la plaça de professor titular d'Història Antiga l'any 1984 i l'Emili la de Prehistòria l'any 1985. Posteriorment, l'any 1999, assoliria la plaça de catedràtic de Prehistòria, ja en el marc de la nova Universitat de Lleida.

D'aquests primers anys (1978-1986) penso que cal destacar també que des de l'any 1981 l’Emili va aconseguir que l'assignatura Arqueología general (Historia, teoría métodos y técnicas) formés part dels primers cursos del pla d'estudis, però sobretot l'endegament, juntament amb l'Arturo, d'una sèrie de cursets d'arqueologia oberts a l'estudiantat, però adreçats especialment a llicenciats i professors d'arreu, que intentaven aprofundir en les problemàtiques més actuals del moment i a la vegada permetien d'alguna manera situar l'Estudi General a l'elit de l'ensenyament especialitzat en Arqueologia, Prehistòria i Història Antiga.

Els cursets, oficialment organitzats (i patrocinats) per l'ICE de la Universitat de Barcelona però coordinats inicialment per ells mateixos, es van endegar l'any 1980 amb l'Oswaldo Arteaga i es repetiren al llarg de divuit edicions fins l'any 1995, els darrers anys amb la col-laboració de la resta de la secció. Hi van passar investigadors i professors de reconegut prestigi, principalment de l'àmbit català i estatal, però també de l'àmbit internacional: Andrea Carandini, Yvon Garlan o Michel Py. ${ }^{3}$

3. I. Oswaldo Arteaga (1980): I Curset d'arqueologia de camp. II. Ricardo Olmos (1983): La ceràmica grega d'època arcaica i clàssica a la península Ibèrica.

III. Mercè Roca (1983): La ceràmica romana imperial (terra sigil.lata).

IV. Andrea Carandini (1985): Estratègia i anàlisi estratigràfica en l'arqueologia dels 80.

V. Ferran Puig, Ramon Maria Puig i Núria Rafel (1986): El Portal de Magdalena. Anàlisi d'una intervenció arqueològica.

VI. Enric Sanmartí (1987). Les ceràmiques de vernís negre (segles VI a I a.C.).

VII. Ma Eugenia Aubet (1988): La colonització fenícia.

VIII. Walter Pagnotta (1989): Història i Arqueologia etrusca. IX. Enriqueta Pons (1990): Hàbitats i estructures domèstiques a Catalunya.

X. Yvon Garlan (1990): Poliorcètica grega i fortificacions indígenes en el Mediterrani centre-occidental.

XI. Jordi Estévez amb la col-laboració de Núria Juan-Muns, Jordi Martínez i Susana Casellas (1991). Arqueozoologia.

XII. Francisco Burillo (1991): Tècniques d'anàlisi en arqueologia espacial.

XIII. Consuelo Mata i Helena Bonet (1992): Urbanismo y organización del territorio ibérico en la Edetania.

XIV. Michel Py (1992): Arqueologia $i$ ordinadors. La informatització del registre gràfic. 


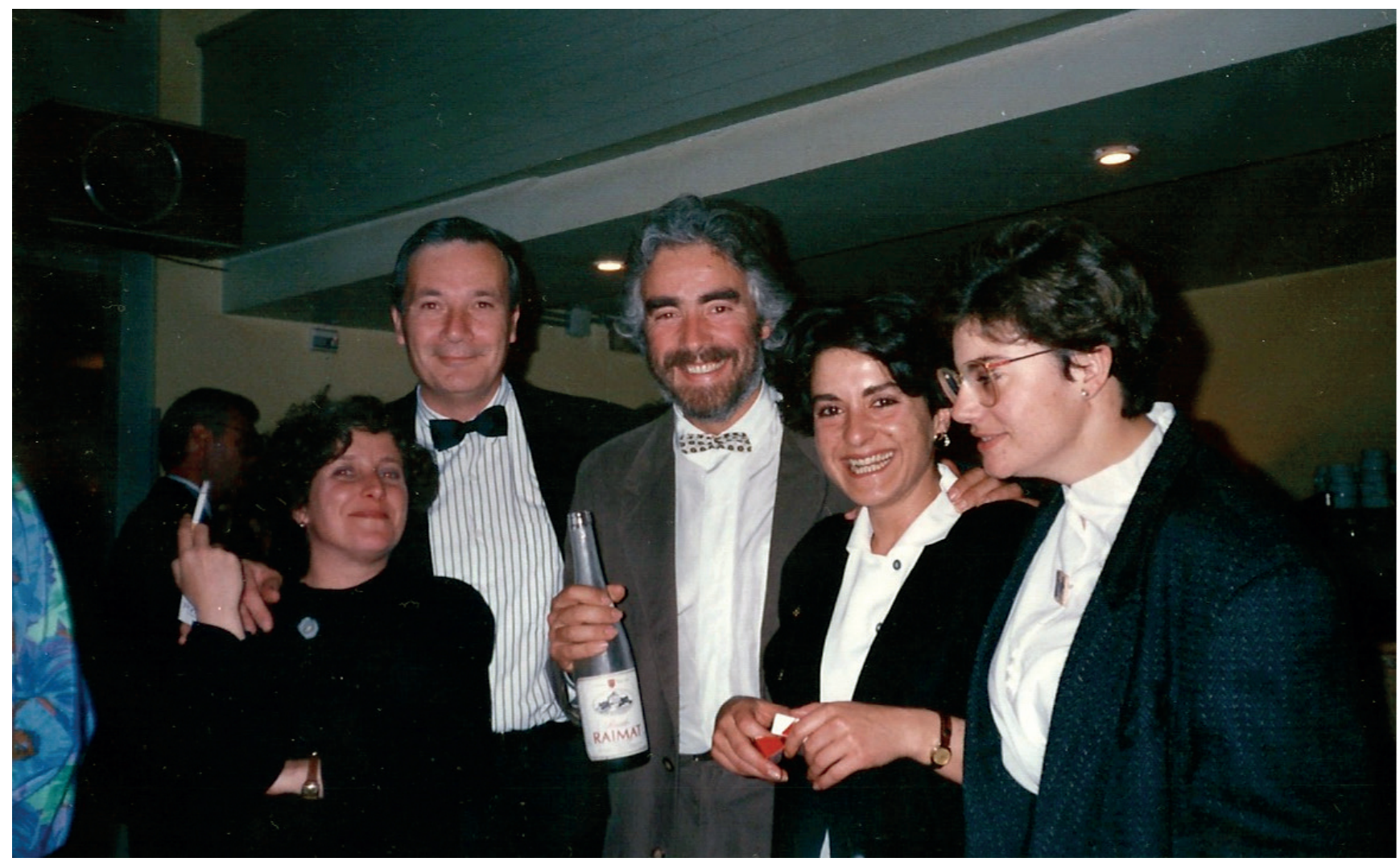

Figura 2. Festa de l'Acadèmia a la Sala Europa de Lleida l’any 1989. D’esquerra a dreta: Anna Oliver, Arturo Pérez, Emili Junyent, Núria Rafel i Maite Miró.

Com deia en explicar la meva pròpia trajectòria, en el pla d'estudis d'aquells anys només s'impartien a Lleida les assignatures comunes dels tres primers cursos i l'Emili i l'Arturo només ho feien a segon i tercer curs. El contacte amb els pocs estudiants amb vocació arqueològica era, doncs, molt reduït i el fet de marxar tot seguit a Barcelona provocava que molts preferissin seguir la seva carrera acadèmica allí, on hipotèticament tindrien més possibilitats d'èxit. No obstant això, hi va haver algunes excepcions i reconeguts investigadors, avui encara en plena activitat, com en Josep Gallart o l'Ignasi Garcés, van gaudir entre 1983 i 1986 de sengles beques predoctorals a l'Estudi General de Lleida, tutelades per l'Emili Junyent.

La incorporació de la Núria Rafel l’any 1987 (figura 2) —els estudis de dret i lletres ja s'havien traslladat a l'edifici del Seminari Diocesà l'any anterior- i poc després (1989) d'en Joaquín Ruiz de Arbulo van suposar un salt qualitatiu espectacular per a la consolidació de les respectives àrees de coneixement i per a poder constituir-se poc després com a grup d'acció conjunta en qualitat d'“Unitat d'Arqueologia,

XV. Paloma Cabrera i Ricardo Olmos (1993): La ceràmica grega a la península ibèrica.

XVI. Carlos Gómez Bellard (1993): Eivissa fenícia i púnica. Estat de la qüestió $i$ noves perspectives.

XVII. Joan B. López (1994): El registre d'excavació i la seva explotació informàtica.

XVIII. Fernado Alonso, Pedro Vicente Castro, Joan Mestres, Rafael Micó i Josep M. Miró (1995): Datació radiocarbònica i calibratge.
Prehistòria i Història Antiga”. Aquell mateix any 1987, l'antiga extensió de Lletres s'havia convertit en l'actual Facultat de Lletres, gràcies a la modificació dels estatuts de la Universitat de Barcelona el curs 1984-1985, la qual cosa va permetre que l'Estudi General es convertís en la Divisió VI de la UB, i consolidar-ne l'autonomia jurídica i organitzativa, l'estructuració amb els seus propis departaments i el reforçament, en definitiva, de la seva autonomia pel que respecta als ensenyaments (Barrull 2009: 51). La unitat s'integrà així en el macrodepartament de Geografia i Història, que gestionava una llicenciatura homònima amb diferents itineraris.

Aquell mateix any 1987 s'aconseguí crear el Laboratori d'Arqueologia, dedicat a la restauració i conservació de materials arqueològics, com un servei adscrit al departament (actualment constitueix un servei cientificotècnic de la Universitat), el qual s'organitzà amb la figura d'un professor responsable (l'Emili) i un tècnic especialista, plaça que fou assolida per Carme Prats, encara avui coordinadora responsable del laboratori.

Faig aquí un incís en la recopilació de l'activitat acadèmica de l'Emili per comentar alguns aspectes de les actuacions generals de la unitat durant aquells anys, el protagonisme de les quals crec que és just repartir a parts iguals entre tots els seus membres. Tot i que els diferents professors/es s'implicarien més o menys en tal o qual projecte, existia un esperit de direcció col-legiada i les reunions per debatre els diferents temes eren sistemàtiques i constants. 
Així, durant la dècada dels noranta la unitat, tot respectant els projectes de recerca individuals de cada investigador/a, emprengué diferents accions conjuntes, especialment projectes de suport al desenvolupament de l'arqueologia urbana. Mitjançant convenis amb l'Ajuntament de Lleida o, més puntualment, amb la Generalitat de Catalunya, s'aconseguí —entre altres aportacions que seria llarg desenvolupar- dissenyar un sistema informàtic de registre i gestió integral del patrimoni històric i arqueològic de la ciutat: Lleid'Arq (Lafuente, Ruiz de Arbulo 1995), el qual, amb canvis substancials pel que respecta al software utilitzat i al disseny informàtic, encara utilitza ara l'estructura conceptual del sistema. No obstant això, la reeixida més significativa fou la fundació l'any 1991 de la Revista d'Arqueologia de Ponent (infra), una eina que, malgrat el reduccionisme geogràfic del nom, naixia amb la voluntat d'acollir també totes les novetats de la recerca arqueològica nacional i internacional, i de convertir-se en un òrgan de debat teòric, metodològic i social sobre l'actualitat de l'arqueologia en general. ${ }^{4}$

La unitat, de la qual l'Emili era el portaveu, es mantingué funcionalment com a tal quan, en el marc de la recentment constituïda Universitat de Lleida (1994), es va produir l'escissió l'any 1995 del Departament de Geografia i Història en tres nous departaments: Geografia i Sociologia, Història de l'Art i Història Social i Història. Va quedar adscrita a aquest darrer i, mantenint l'esperit d'acció conjunta, aconseguí el reconeixement com a "Grup de Recerca Consolidat" en la nova tipologia de grups que establia el Pla de Recerca i Innovació de la Generalitat de Catalunya (2005-2008): Grup de Recerca en Arqueologia, Prehistòria, Història Antiga - GRAPHA: SGR 200500798. Posteriorment, renovaria aquest reconeixement durant les convocatòries següents (2009 SGR 198; 2014 SGR 273), tot i que en aquesta darrera es va perdre el finançament. L'Emili, per decisió unànime, va signar com a investigador principal totes aquestes convocatòries, però val a dir que no va exercir mai una direcció centralitzada, ja que es respectava la gestió autònoma dels diferents projectes que integraven les activitats de recerca del grup.

Passant al capítol de la seva participació en les tasques de gestió general universitària, cal dir que la seva implicació ha estat, tot i que des de diferents fronts, gairebé constant fins l'any 2007, en què, després de set anys com a degà, decideix consagrarse més intensament a la recerca, especialment a la fortalesa dels Vilars.

Ben aviat, doncs, l'any 1978, assumí el càrrec de coordinador d'estudis i delegat del degà de la Facultat de Geografia i Història de la Universitat de Barcelona -llavors l'historiador Emili Giralt-, tasca que desenvolupà fins l'any 1982. Posteriorment, l'any 1986, quan l'Estudi General —com ja he assenyalat abans-s'havia convertit en la Divisió VI de la UB,

4. Crec que és just reconèixer que tant en la creació del laboratori com de la Revista d'Arqueologia de Ponent fou decisiu el suport d'en Víctor Siurana, llavors president de l'Estudi General i més tard (1992-1993) president-rector de la Comissió Gestora de la Universitat de Lleida durant el seu procés constituent. fou nomenat de nou cap d'estudis de l'ensenyament de Geografia i Història i continuà exercint aquest càrrec després de la creació de la Facultat de Lletres (1987), fins l'1 de març de 1994, poc abans de finalitzar el procés constituent de la nova Universitat de Lleida amb l'aprovació pel Claustre dels seus Estatuts el 27 d'octubre d'aquell mateix any.

Des del 1993, però, la seva militància en el Sindicat Universitari de CCOO i l'èxit d'aquesta formació en els diferents comicis, l'havia portat a ser elegit president de la Junta de Personal Acadèmic, càrrec que desenvolupà fins l'any 1999 i que li permetia formar part, com a membre nat, del Claustre de la Universitat des d'on exercia la tasca d'agent social i portaveu de les reivindicacions del personal docent funcionari, en una època que la ideologia i el debat sobre el model d'universitat encara impregnaven l'activitat sindical.

Poc després, l'any 2001 fou elegit degà de la Facultat de Lletres, càrrec que - com he dit- desenvolupà durant dos mandats fins l'any 2007. Va emprendre aquesta nova etapa conscient de la conjuntura difícil que travessava la UdL i la facultat en particular, que des del curs 1996-1997, amb quasi 1.400 alumnes matriculats, havia passat a 600 el curs 2004-2005 i a més enfrontant-se a un repte nou, com era endegar el procés d'adaptació a l'Espai Europeu d'Educació Superior (EEES). Però ho va fer carregat d'illlusió i energia i l'equip degà que el va acompanyar pot donar fe del ritme de treball constant i de la intensa dedicació que es va autoimposar.

No puc recollir aquí totes les aportacions que la seva tasca va comportar, però des de l'inici del seu mandat es marcà com a objectiu l'elaboració d'un Pla Estratègic de la Facultat, tasca que va desenvolupar amb una metodologia innovadora que es regia pel principi de la màxima participació del conjunt de la comunitat universitària i dels agents socials, incorporant a la vegada els serveis d'una empresa facilitadora amb experiència reconeguda (Momentum Networking \& Management Worldwide) i l'assessorament de Josep Maria Bricall, com a valor afegit. El document resultant "Planificació estratègica de la Facultat de Lletres (2005-2010)" fou informat favorablement per la Junta de Facultat del 28 de juny de 2005, però - per raons de casuística molt diferent- no va arribar mai a implementar-se completament, ni durant el seu mandat, ni per part dels seus successors. El nou pla, pel que respecta a la docència, apostava entre altres coses per la fórmula del $3+2$ que preconitzava la Declaració de Bolonya, però aquesta opció va quedar frenada tant a Catalunya com a la resta de l'Estat per l'oposició de les mateixes universitats.

No obstant això, la Facultat de Lletres fou la primera de Catalunya a adoptar de manera conjunta (set titulacions) la nova metodologia dels crèdits ECTS amb el suport d'un d'Ajut a Projectes d'Innovació Docent (2004-2005) que ell liderava i que finançava la UdL. Comptant amb el suport dels estudiants, endegà també un projecte d'elaboració del portafolis o carpeta de l'estudiant i un pla d'acció tutorial, en el marc dels plans pilot d'adaptació a l'EEES; reorganitzà els espais de docència i recerca de la facultat, posà en marxa un nou pla de seguretat i, en un altre ordre de coses, aconseguí que la nova 
titulació de Comunicació i Periodisme Audiovisuals (2003-2004) tingués la seu a la Facultat de Lletres.

Pel que respecta a la docència, he de dir que és un d'aquells professors que gaudia donant classes i del contacte directe amb els estudiants. Va impartir docència tant en els estudis de llicenciatura/grau com en els programes de tercer cicle, que des de 1989 van incorporar-se a l'ensenyament de Lletres de la UdL. Impartia assignatures tant de l'àrea de Prehistòria com de les d'Arqueologia i Història Antiga, però crec que n'hi ha dues que cuidava amb especial afecte: Arqueologia general, que va impartir des de 1981 fins a la seva jubilació, i Cultura Ibèrica, que va aconseguir integrar en el pla d'estudis l'any 1996 i va desenvolupar també fins al final.

Durant l'estiu, va participar en totes les campanyes d'excavacions arqueològiques que es desenvolupaven als Vilars, i va fomentar des de l'inici que aquestes constituïssin una escola d'aprenentatge amb reconeixement oficial. D'aquesta manera, va promoure i dirigir l'any 1998 un curs de postgrau de formació d'investigadors i d'extensió universitària (12 crèdits): Anàlisi, excavació i gestió integral de jaciments arqueològics, que es desenvolupava als locals de l'Ajuntament d'Arbeca i al jaciment dels Vilars, el qual l'any següent es traduí en dos cursos sobre Investigació i gestió del patrimoni arqueològic, adreçats a llicenciats i estudiants amb un reconeixement de 6 crèdits de lliure elecció. Aquests cursos van comptar amb el suport econòmic del Patronat de Promoció Econòmica de les Terres de Lleida (Diputació de Lleida). Anys després, des del 2004 fins avui, les campanyes als Vilars es convertirien en cursos teoricopràctics d'arqueologia de la Universitat d'Estiu de la UdL.

Ha dirigit, d'altra banda, nombroses tesis de llicenciatura, TFG i TFM i un total de cinc tesis doctorals. ${ }^{5}$

\section{Trajectòria investigadora i producció científica}

El terreny ha estat des de l'inici de la seva carrera la seva "biblioteca" preferida. És impressionant observar com, encara ara amb setanta-dos anys, vibra, s'emociona i s'apassiona en l'excavació, i transmet aquest sentiment a tots els que l'envoltem. Cada passada de paletí (o cada cop de pic, que és el seu instrument preferit) li genera una allau d'hipòtesis i qüestions

5. - 1990. Ignasi Garcés: Assimilació, resistència $i$ canvi a la romanització en el món ilerget (Aproximació a l'Horitzó Ibèric Tardà $i$ les seves pervivències a les comarques de plana de les províncies d'Osca i Lleida). Estudi General de Lleida.

-1991. Florencio Mayoral: Análisis de las variables sociales reconocidas en las necrópolis del Horizonte Ibérico Antiguo y reconstrucción de la sociedad en el Montsiá-Bajo-Maestrazgo. Universitat Autònoma de Barcelona.

-1997. Natàlia Alonso: Agricultura a la plana occidental catalana durant la protohistòria. Universitat de Lleida (Diploma de Doctorat Europeu i Premi Extraordinari de Doctorat).

-2000: Joan B. López: L'evolució del poblament protohistòric a la plana occidental catalana. Models d'ocupació del territori $i$ urbanisme. Universitat de Lleida (Premi Extraordinari de Doctorat).

-2018: Joan Bernal: Les cisternes de Vilars (Arbeca, les Garrigues) i Roques de Sant Formatge (Seròs, el Segrià). Aportacions a la caracterització de l'ibèric ple en l'àrea ilergeta a través de l'estudi dels materials ceràmics (pendent de defensa).

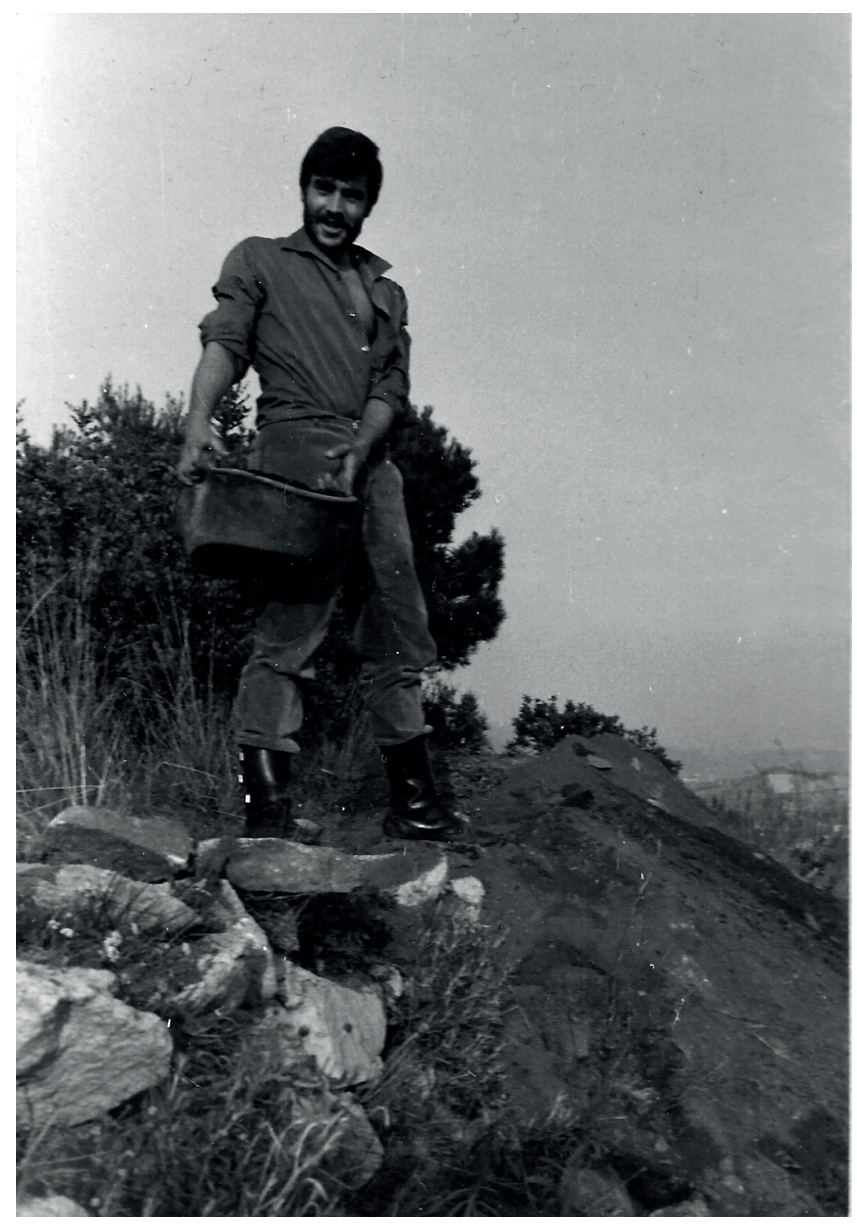

Figura 3. L'Emili a l'excavació de Mas Boscà (Badalona, Barcelonès), l’any 1969.

que voldria resoldre abans de donar la següent. A la seva vora s'aprèn com cal plantejar-se preguntes abans, durant i després de l'excavació. Com ell mateix ha explicat (Junyent 2013: 275), va col-laborar amb Joan Maluquer en nombroses excavacions de variada cronologia i temàtica. ${ }^{6}$ També per encàrrec seu i en col-laboració amb Vicenç Baldellou, excavà el 1968 una casa ibèrica a l'oppidum de Mas Boscà (Badalona), que acabà resultant decisiva, atès que el seu estudi es convertí en la tesi de llicenciatura i va determinar la inclinació vers el món ibèric (Junyent, Baldellou 1972a; 1972b).

Mentre prepara la tesi doctoral (1970-1974) concentra la seva activitat en diferents oppida del territori ilerget a la recerca, en definitiva, de les dades que han de facilitar-li la informació necessària per poder dur-la a terme. D'aquesta manera, efectua diferents

6. L'any 1968 a la Cova de Berrobería (Urdax, Navarra): magdalenià-azilià; el 1969 a la Cova de Muricecs (Llimiana, Pallars Jussà): musterià-edat del bronze; el 1970 al Barranc d'en Fabra (Amposta), necròpoli neolítica (Baldellou 1971-1972); el 1969-1970 al Camp Triangular del Puig de Sant Andreu (Ullastret, Baix Empordà): ibèric; el 1970-1971 a la necròpolis ibèrica de Mianes (Santa Bàrbara, Montsià); el 1971 al poblat de la Ferradura (Ulldecona, Montsià): primera edat del ferro i al poblat ibèric del Molí de l'Espígol (Tornabous, l’Urgell), i el 1973 a l'oppidum de Margalef (Torregrossa, Pla d'Urgell) (Junyent 2013: 275). 
sondejos - "talls estratigràfics" en la terminologia del moment- a Roques de Sant Formatge (Seròs, Segrià) (Junyent 1973a; 1973b ), els Vilars (Aitona, Segrià) (Junyent 1982c), el Pilaret de Santa Quitèria (Fraga, Baix Cinca) (inèdit) i el Tossal del Molinet (el Poal, Pla d'Urgell) (Junyent 1982a; Junyent, López 2015). En aquestes intervencions sovint hi participaven companys de carrera o promoció com Oriol Granados, Vicenç Baldellou, Francesc Gusi, Carme Olària, Miquel Cura, Francesc Tarrats, Rosario Navarro, Elisabeth Huntingford, Josep Tarrús... —esmento els que jo sé- que després han esdevingut també referents de la recerca arqueològica catalana i peninsular i amb els quals l'Emili ha continuat mantenint una entranyable relació. ${ }^{7}$

La seva tesi va permetre, entre altres coses, replantejar a l'alça la cronologia de la iberització, reconèixer la importància de la presència fenícia en els seus orígens en tota la façana llevantina, des de Múrcia fins a l'Hérault, i revaloritzar el paper dels ilergets dins del panorama general del món ibèric. Però crec que una de les seves aportacions principals d'aquesta etapa va ser emfasitzar en la necessitat d'un rigorós respecte a l'estratigrafia arqueològica en la metodologia d'excavació i registre, experimentant fins i tot amb aproximacions llavors innovadores com el mètode de "projecció a l'estrat", que l'Oswaldo Arteaga, col-laborador del Deutsches Archäologisches Institut i de la Universidad de Granada, estava desenvolupant (Los Saladares, Oriola, Vinarragell, Borriana) i sobre el qual va ser convidat a impartir l'any 1980 el I Curset d'Arqueologia, abans esmentat. Les pràctiques es van efectuar en una nova intervenció al Tossal del Molinet i posteriorment el mètode també l'aplicaria en les excavacions de la Paeria de Lleida (infra).

Un cop fou a l'Estudi General, l'any 1975 tingué el seu primer contacte amb l'arqueologia urbana, el qual no pot dir-se que l'efectués amb gaire bon peu. Unes obres d'entrada desaconsellades a la plaça Sant Joan de Lleida (al llarg dels temps també plaça del Mercat, de la Constitució o d'Espanya) posaren al descobert les restes de l'absis de l'antiga església medieval de Sant Joan enderrocada l'any 1868. Aquesta interpretació li valgué l'enfrontament en solitari amb els arqueòlegs i les autoritats locals, fins i tot amb els tècnics de la Dirección General del Patrimonio Artístico y Cultural, els quals, davant la presència de carreus encoixinats en la construcció, la interpretaven com un edifici romà. La lectura positiva de l'assumpte és que, tot i que de manera parcial i molt malmesos, es van documentar per primera vegada in situ alguns nivells d'època ibèrica tardana (segle II ANE), subjacents a altres d'època romana imperial (Junyent 1982e; 1983; Junyent, Pérez 1994; 1995; Gallart et al. 1985: 13-23).

L'interès per la ciutat, però, s'incrementà amb l'arribada a l'Estudi General de l'Arturo Pérez l'any 1978 i junts enprengueren un primer projecte de recerca específic: Iltirda-Ilerda, que comptà amb finançaments

7. La comunitat científica ha sofert en els darrers anys la pèrdua prematura d'alguns d'ells: Miquel Cura (2002), Francesc Gusi (2012), Vicenç Baldellou (2014); des d'aquí vull fer públic el meu record i modest homenatge vers tots ells, tant pel que van aportar a l'arqueologia com per la seva vàlua humana. diversos $^{8}$ al llarg dels anys (1981-1986). Al marge de l'interès personal en l'estudi de les respectives èpoques, el projecte hauria de permetre construir sobre bases científiques sòlides, provinents d'excavacions rigoroses, una història de la ciutat fins llavors bastida quasi exclusivament a partir de fonts escrites i troballes fora de context. Ben aviat comptaren també amb la col-laboració en aquesta empresa (infra) de la Núria Rafel, que — com ja hem dit- l'any 1983 havia arribat a Lleida per exercir com a arqueòloga territorial.

D'aquesta manera, l'any 1981 endeguen les excavacions a les dependències subterrànies de la Paeria on, si ho plantegem en funció dels interessos, els resultats foren més propicis a l'Arturo ja que els nivells documentats se situaven en el segle I ANE i els segles IV-v DNE, i mancava l'etapa intermèdia. ${ }^{9}$ Es tractava, a més a més, de construccions marginals amb relació a la trama urbana de la ciutat, que poc aportaven així al coneixement de la Ilerda romana. Es documentaren també, en la part més propera al riu, les restes d'una potent construcció esglaonada, que s'interpretà com uns banys àrabs (Junyent, Pérez 1983; 1985; 1994; Gallart et al. 1985: 25-38). Més recentment (Loriente 2016) s'ha proposat que aquesta construcció podria formar part d'un port fluvial de l'antiga Medina Larida.

Junts dugueren a terme l'estudi d'altres jaciments romans del terme com la Fonteta del Grealó (Lleida, Segrià) (Junyent, Pérez 1982) i, amb la publicació dels resultats, aconseguiren que Lleida se situés davant la comunitat científica i l'opinió pública en general, ${ }^{10}$ en la llista de les ciutats romanes de Catalunya, en qualitat de jaciment amb un gran potencial arqueològic que calia investigar i preservar (Junyent, Pérez 1983).

I és que durant aquells anys, que coincidiren amb la realització de l'excavació de l'Antic Portal de Magdalena (1984-1987), el tractament de les restes arqueològiques en sòl urbà constituïa un debat obert tant a Lleida com a la resta de ciutats catalanes. No puc ara tractar aquest tema amb detall, però per aquelles dates la Paeria duia a terme modificacions

8. Paeria de Lleida, Vicerectorat d'Investigació de la Universitat de Barcelona, entre altres.

9. Excavacions posteriors efectuades l'any 1997 per Xavier Payà en una sala contigua, van documentar també un mur d'època flàvia, amb la qual cosa no sembla que tot l'indret estigués deshabitat durant l'Alt Imperi (Gil et al. 2001: 163).

10. Els debats a la premsa local eren especialment freqüents durant aquells anys i l'Emili i l'Arturo no dubtaren a utilitzar aquesta plataforma com un mitjà per sensibilitzar l'opinió pública envers la protecció del patrimoni. En recullo alguns exemples:

- Junyent, E. (1985). La Magdalena y la arqueología de la ciudad (I). Segre, Lleida, 22 de gener de 1985.

- JunYent, E. (1985). El arqueólogo ante la conservación de los restos (II). Segre, Lleida, 23 de gener de 1985.

- Junyent, E. (1985). La Administración ante la conservación de restos arqueológicos (y III). Segre, Lleida, 24 de gener de 1985.

- Junyent, E., Pérez, A. (1985). Los sótanos de La Paeria y la historia antigua de Lleida. Segre, Cultura, Quadern 81, Lleida, 7 d'abril de 1985.

- Junyent, E., Pérez, A. (1986). El Portal de Magdalena y la arqueología de la ciudad. Segre, Cultura, Quadern 117, Lleida, 1 de juny de 1986. 
substancials en el Pla General Municipal del 1979, que es concretaren en l'elaboració de diferents Plans Especials com el del Canyeret (1983) o el del Centre de Lleida (1986), i el debat al respecte estava més viu, inclús, que en altres ciutats.

És en aquest punt que, juntament amb la Núria Rafel, formaren pinya en la defensa de la necessitat del tractament unitari de la ciutat com a jaciment, d'una planificació de les intervencions i d'una gestió de les dades centralitzada (Junyent, Pérez, Rafel 1985; 1988; 1989a; 1989b). En qualsevol cas, la Paeria fou la darrera excavació efectuada per la Universitat a la ciutat, ${ }^{11}$ ja que, de mutu acord amb l'Ajuntament, es decidí que l'estratègia correcta era potenciar la creació d'un servei municipal d'arqueologia i reconduir la col-laboració a la preparació d'un sistema unificat de registre - l'esmentat Lleid'Arq — i a potenciar la revista d'arqueologia i el laboratori de restauració; així, l'any 1992 es dotà, com a primer pas, una plaça d'arqueòleg municipal que ocupà Anna Oliver (Gil 2017).

Aquelles primeres accions conjuntes constituïren l'embrió d'una relació que, amb intensitat variable, s'ha mantingut estable fins avui i un dels fruits més significatius fou la implicació de la Paeria en la creació l'any 1990 de la sèrie Monografies d'Arqueologia Urbana i de la Revista d'Arqueologia de Ponent l'any 1991,12 la qual a més a més aglutinava també la Diputació de Lleida a través de l'Institut d'Estudis Ilerdencs; és a dir, el conjunt d'institucions actives en matèria d'arqueologia a la ciutat $i$ al territori. La sèrie monogràfica malauradament no va tenir continuïtat $i$ desaparegué l'any 1993, després de publicar-ne cinc números.

Durant aquests anys, però, l'Emili no abandona tampoc la recerca en protohistòria, ara orienta la seva activitat de camp cap al substrat receptor del procés d'iberització. Així, juntament amb Josep Gallart —el seu primer becari predoctoral (1983-1986) - i el Grup de Recerques Arqueològiques de "La Femosa" (Artesa de Lleida) efectuen una intervenció a la necròpolis de la primera edat del ferro de la Pena (Torregrossa, Pla d'Urgell) l'any 1977 (Junyent 1982d) ${ }^{13}$ i l'any 1979 duen a terme un nou sondeig al poblat de la Pedrera (Vallfogona de Balaguer-Térmens). Participa també (1981-1983) en una intervenció conjunta amb membres del Servei d'Arqueologia de l'IEI (Joan

11. Tot i així, durant els anys 1994-1995, el llavors acabat de crear Grup d'Investigació Prehistòrica (infra) col-laboraria en l'excavació efectuada dins del terme municipal de Lleida en el jaciment de Roques del Sarró (Equip Sarró 2000).

12. Per part del llavors encara Estudi General de Lleida, formaven part del nucli fundador de la revista: Emili Junyent, Joan B. López, Arturo Pérez, Carme Prats, Núria Rafel i Joaquín Ruiz de Arbulo, que constituïren el primer Consell de Redacció, i Ángel Lafuente, que actuà com a secretari. Durant aquests primers anys (1991-1995), la direcció es feia de manera conjunta; posteriorment fou assumida per Joaquín Ruiz de Arbulo (1996), Emili Junyent (1997), Francesc Tuset (1998), Arturo Pérez (1999 i 2005-2009), Núria Rafel (2000, 2003-2004 i 2010-2013), Joan B. López (2001-2002) i Natàlia Alonso, des del 2014 fins ara (Alonso 2015: 8).

13. D’aquesta intervenció només en va publicar un breu avanç. L'estudi el dugué a terme Josep Gallart en el marc de la seva tesi de llicenciatura (Gallart 1982), de la qual en va publicar després un petit treball monogràfic (Gallart 1988).

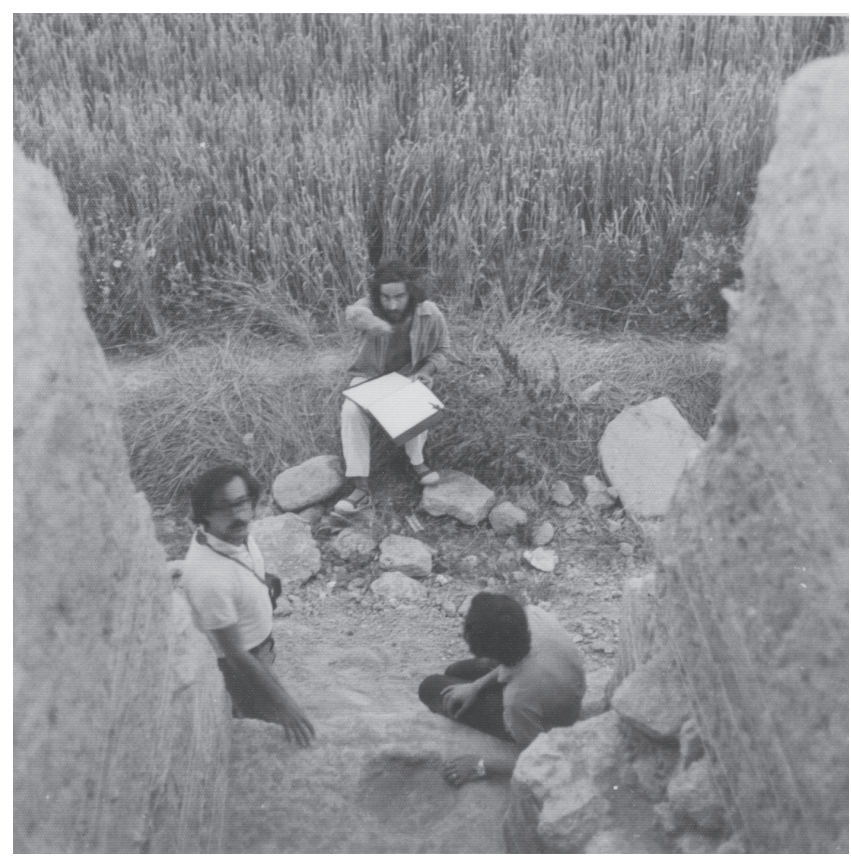

Figura 4. Excavació del Tossal del Molinet (el Poal, Pla d'Urgell), l'any 1973. A l'esquerra, Josep Tarrús; al centre, l'Emili.

Ramon González i Josep Ignasi Rodríguez) i de la UAB (Josep Lluís Maya) en l'excavació del poblat del bronze final de Carratalà (Aitona, Segrià) (Junyent et al. 1983), actuació que no veié la llum, però, fins molts anys més tard (Junyent et al. 2002).

L'excavació del poblat de la Pedrera, publicada en una monografia alguns anys després (Gallart, Junyent 1989), crec que fou l'espoleta que provocà un canvi significatiu en la seva visió de la protohistòria a la plana occidental catalana. És una llàstima que aquest llibre, editat per la UdL en la col-lecció "Espai i Temps", no tingués la difusió que mereixia. El jaciment, excavat per Joan Maluquer l'any 1958, constituïa un referent dins la protohistòria catalana perquè es tractava de l'única estratigrafia de referència per observar la transició sense solució de continuïtat entre els Camps d'Urnes, la primera edat del ferro i l'època ibèrica. A més, amb algunes llacunes temporals (Ruiz Zapatero 1985), podia contrastar-se amb l'evolució de la necròpolis homònima ${ }^{14} \mathrm{i}$, de retruc, posava damunt la taula temes rellevants com l'origen de la primera edat del ferro a Catalunya.

La continuïtat entre el primer ferro i l'època ibèrica ja l'havia observat al Tossal del Molinet (el Poal, Pla d'Urgell) (figura 4), però constituïa també una dada aîllada que requeria contrastació. El poblat de la Pedrera no tan sols ho confirmaria, sinó que a més a més posaria de manifest la presència de nivells pre Camps d'Urnes, anteriors al bronze final II, amb arquitectura en pedra. Aquesta dada el porta de seguida a interessar-se per l'origen del fenomen a partir d'incidir en temes com l'origen del sedentarisme a la plana i l'evolució de les pràctiques productives.

14. L'Emili també s'interessà per la necròpolis i poc després va encarregar a na Mercè Plens una revisió al respecte, que culminaria amb la seva tesi de llicenciatura (Plens 1986). 
Pel que respecta al primer problema, duu a terme una actualització exhaustiva de les dades existents des de l'eneolític i, pel que respecta al segon, compta de seguida amb les aportacions de Natàlia Alonso, a la qual dirigia la tesi de llicenciatura (Alonso 1992) i que, juntament amb Ramon Buxó (Alonso, Buxó 1989; 1995), estudiaven les restes paleobotàniques de la Cova de Punta Farisa (Fraga, Osca), un abric del bronze mitjà, excavat per José Luis Maya els anys 1988-1989 (Maya, Francés, Prada 1993).

En el col-loqui d'Arles de 1989: Habitats et structures domestiques en Méditerranée occidentale (Junyent 1989) presenta per primera vegada les línees mestres d'un nou constructe teòric en el qual l'aparició reconeguda d'un primer urbanisme a la plana durant el bronze final II (els Camps d'Urnes antics) ja no és vista com un fenomen sobtat i importat, sinó com hereu d'una evolució interna del poblament que s'inicia amb l'aparició de les primeres aldees estables durant el bronze antic i continua amb el desenvolupament dels primers poblats amb arquitectura en pedra durant el bronze mitjà-recent.

La relativització de la incidència dels Camps d'Urnes s'accentuà amb la publicació dels primers resultats arqueobotànics de Punta Farisa, en els quals es demostra la pràctica plenament desenvolupada, ja durant el bronze mitjà, d'una agricultura tant de cereals d'hivern com de primavera (Alonso, Buxó 1989; 1995), i s'accentuà més quan aparegueren els resultats de la necròpolis dels Castellets-II (Royo 1996), en els quals es fa palès que el nou ritual de la incineració tampoc s'adopta de manera sobtada durant el bronze final-II i que no es generalitza fins als Camps d'Urnes Recents (bronze final-III). Les diferents reflexions sobre l'autoctonisme i la singularitat del procés respecte a la resta del nord-est peninsular són gradualment publicades (Junyent 1991a; Junyent, Lafuente, López 1994) i al col-loqui de Lió de l'any 1998: ${ }^{14} \mathrm{C}$ et Archéologie, es proposa per primera vegada (Alonso et al. 1999) l'existència d'un grup cultural específic durant l'edat del bronze a la plana occidental catalana, el grup del Segre-Cinca, i un marc cronològic renovat a partir de noves datacions absolutes, que l'equip havia obtingut en el marc d'un projecte de recerca específic.

La crítica de la validesa del concepte dels Camps d'Urnes va anar madurant, considerant-los un constructe arqueològic superat i inexistent en la realitat, basat en l'ús i abús del mateix concepte de "cultura arqueològica", de tal manera que l'Emili fins i tot reclamà, de vegades amb vehemència provocadora, el seu abandonament (Junyent 2002a: 32). Per aquelles dates, jo havia recollit el testimoni d'aquest nou discurs i sota la seva direcció desenvolupava la meva tesi doctoral (López 2000) en la qual la caracterització d'aquest grup constitueix l'eix central.

La comunitat científica catalana i de la resta de l'Estat ha acceptat amb reserves aquesta nova formulació, però ningú l'ha refutada i continua sent l'eix que regeix l'activitat investigadora de l'equip.

\section{La fortalesa dels Vilars}

L'any 1985 es van endegar les excavacions arqueològiques als Vilars (Arbeca, les Garrigues) sota el guiatge d'Ignasi Garcés (llavors becari predoctoral de l'Emili) i ell mateix. L'Emili coneixia l'existència del jaciment des de l'any 1974 i, com ell explica, "tot va començar amb una capsa de sabates", ${ }^{15}$ una capsa amb materials dels Vilars que un estudiant li va mostrar quan era a Tarragona i que poc imaginava seria decisiva en el desenvolupament de la seva activitat investigadora (figura 5).

Jo no sé què hauria passat si hagués obtingut el suport per part de les institucions per endegar un projecte de recerca i recuperació patrimonial global en el Baix Segre, ${ }^{16}$ fita que s'havia plantejat després de la intervenció de neteja, consolidació i aixecament planimètric de l'oppidum de Gebut (Soses, Segrià) l'any 1987, un jaciment vers el qual sentia una atracció especial com a principal exponent llavors de l'urbanisme ilerget. Però, per sort o no, la Història el va portar a concentrar tots els seus esforços als Vilars. No m'estendré ara en la història de les investigacions en el jaciment, relat que hem publicat recentment (Junyent 2014a; Junyent, López 2016), però sí que incidiré en alguna de les seves principals aportacions i en un aspecte menys conegut com és el paper del grup de recerca que es va crear al seu voltant: el Grup d'Investigació Prehistòrica, el qual d'alguna manera constitueix l'escola que llega per al futur.

Pel que respecta al jaciment, la descoberta de la fortalesa amb les seves singulars característiques, entre elles l'existència d'un camp frisó, va obrir un inesperat camp de recerca que ha permès aportar al coneixement sobre el món ibèric ilerget aspectes desconeguts, tant sobre el substrat existent durant la primera edat del ferro (775-550 ANE) com sobre el seu propi desenvolupament econòmic i social durant els segles posteriors (550-300 ANE).

$\mathrm{Al}$ mateix temps, l'estudi de la seqüència interna del jaciment ha permès construir un discurs que afecta el conjunt de la Ilergècia oriental i avui se sap que en aquesta àrea es va produir durant els segles VIII-VI ANE un procés de jerarquització territorial dels assentaments, articulada al voltant de centres de poder fortificats, dels quals la fortalesa dels Vilars, amb les seves espectaculars i ostentoses defenses (muralla, torres, camp frisó, fossats), n'és avui el referent més emblemàtic $\mathrm{i}$ més ben conegut, però existien també al Molí de l'Espígol (Tornabous, l'Urgell), a Plaça del Vell Pla a Guissona (la Segarra) o al Castell de l'Albi (les Garrigues). Aquesta estructuració, segurament, va experimentar modificacions a inicis de l'ibèric antic (550-450/425 ANE), però alguns d'aquests nuclis van continuar mantenint la seva hegemonia fins i tot

15. "Emili Junyent Sànchez, fill adoptiu d'Arbeca", entrevista publicada pels editors de la revista d'Arbeca La Borrassa, n 13, juliol 2008: 38-41.

16. La necessitat d'aquest projecte la va formular en la memòria de la intervenció: JunYENT, E. (1987). El poblat ilerget de Gebut (Soses, Segrià). Memòria de 1987 i proposta per a 1988. Estudi General de Lleida, Lleida. <http://calaix.gencat. cat/handle/10687/9074? show=full $>$. Per aquelles dates, la Núria Rafel (IP) havia endegat també un projecte, finançat pel Ministerio de Educación y Ciencia, sobre el món funerari en aquesta àrea: PB88-0455: Necrópolis tumulares del Valle del Segre y Bajo Aragón. Caracterización e interacciones. Su relación con los aportes europeos y mediterráneos, en el qual l'Emili també hi col-laborava. 


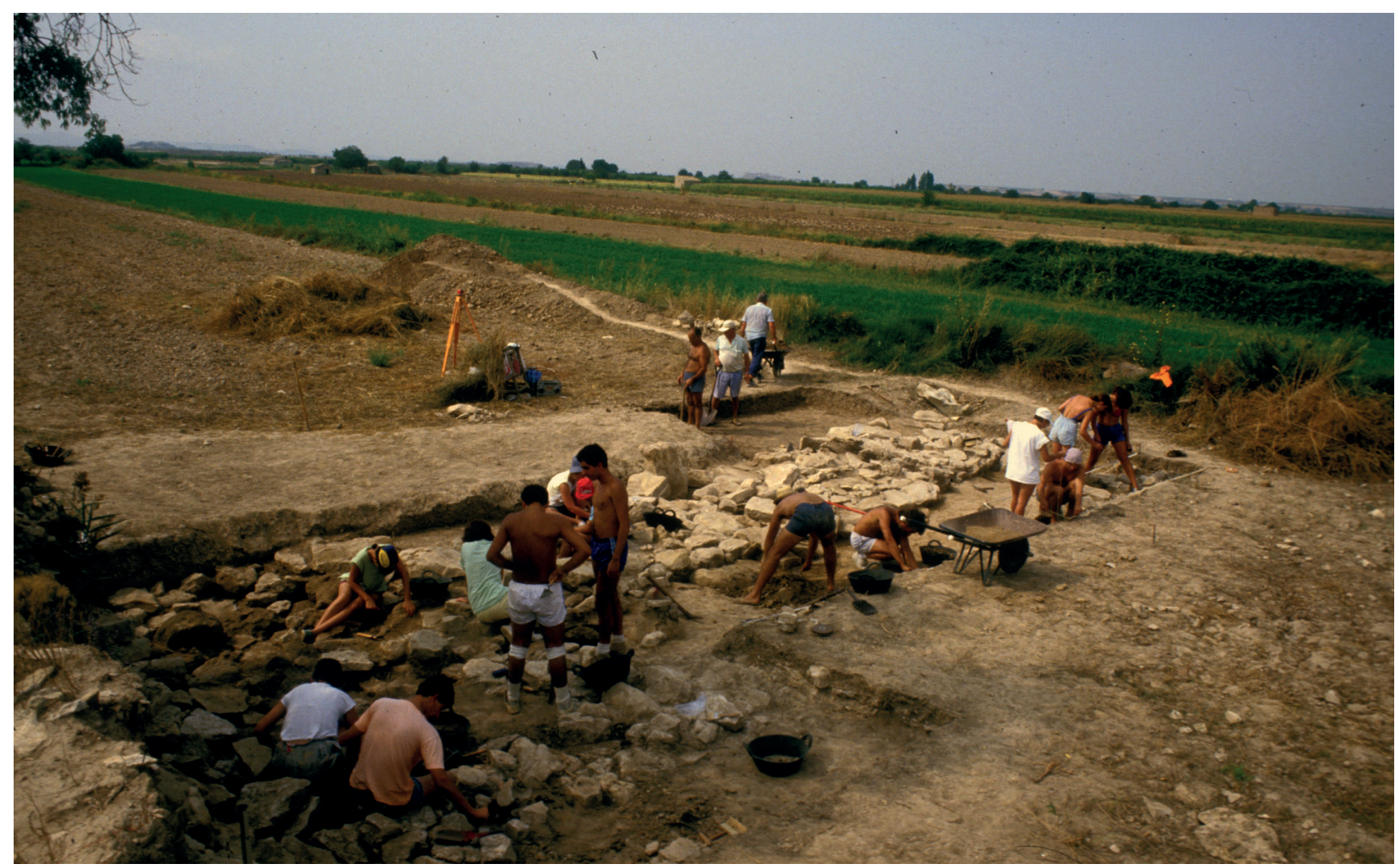

Figura 5. Inici de l'excavació de la muralla dels Vilars d'Arbeca l’any 1987.

durant l'ibèric ple (450/425-200 ANE) (Junyent 2015; Junyent, López 2015, amb la bibliografia). A més a més, la lectura poliorcètica dels elements més significatius de la fortificació (rampa, pou-cisterna, fossat) han suposat una aportació clau a la comprensió de la filiació i la complexitat de la fortificació ibèrica i a qüestions bàsiques sobre la guerra ibèrica (defensa passiva/defensa activa, setge $\mathrm{i}$ assalt...) i, més indirectament, a temes concrets com la gestió i els usos de l'aigua, el cavall o els mercenaris. Igualment, la interpretació en el territori ha convertit la fortalesa en paradigma d'un dels camins del trànsit dels cabdillatges vers l'estat arcaic.

D'altra banda, un ampli projecte de recerca interdisciplinari ha permès caracteritzar els trets específics de les pràctiques agrícoles i ramaderes al llarg de tota la sequència i el desenvolupament d'una siderúrgia local des d'inicis del segle vIII; la producció comunitària i centralitzada de productes tan bàsics com el pa, símptoma d'una estructura social interna fortament cohesionada, almenys des d'inicis del segle VII ANE; el processament dels cereals amb una tecnologia innovadora com és el molí rotatori de palanca des de l'ibèric antic, o obtenir un ampli ventall de dades que ens informen sobre l'evolució de la cultura material (ceràmiques, objectes metàl-lics), el comerç (vaixella de luxe, productes exòtics com el peix marí...) o les pràctiques relacionades amb el món simbòlic i religiós: temples públics, enterraments en l'hàbitat de fetus de cavall, perinatals, ovicàprids... (Junyent, López 2016, amb la bibliografia).
Aquesta és una ràpida síntesi, darrere de la qual hi ha moltes pàgines escrites $\mathrm{i}$ molts viatges arreu del país i d'Europa per donar a conèixer els resultats obtinguts en congressos i reunions científiques i aconseguir per part de la comunitat científica i les institucions gestores del patrimoni el reconeixement de la importància dels Vilars. Són desenes d'articles, que d'alguna manera supleixen l'absència d'una monografia (o vàries) de síntesi, una de les mancances que alguna vegada se li ha retret i que en aquests moments intentem pal-liar. Els Vilars, però, també ha constituiit una de les fonts d'informació bàsiques per al desenvolupament de les tesis doctorals - ja esmentades - de la Natàlia Alonso, la meva o, més recentment, de l'Ariadna Nieto (2012), en aquest cas codirigida per l'Armelle Gardeisen i jo mateix; de l'Andrés Currás (2012), dirigida pel Santi Riera; de la Sílvia Vila (2018), codirigida per la Natàlia Alonso i la Raquel Piqué, i finalment la del Joan Bernal.

Però el fet que m'agradaria ara posar en valor és que aquests resultats s'han obtingut en el marc de l'aplicació constant de metodologies de recerca innovadores, que també han contribuït a l'avanç de l'arqueologia catalana i la recerca en general. Esmentaré només dues aportacions. La primera afecta el concepte intrínsec d'investigació arqueològica. Quan després dels dos primers anys d'intervenció preventiva (1985-1986) s'endega el primer projecte de recerca en el jaciment, es defineix una estratègia i metodologia d'intervenció, que avui sembla normal, però que en aquells moments era pionera en alguns dels seus 
aspectes parcials i com a concepció global aplicada a la protohistòria: l'excavació en extensió (fora dels nuclis urbans), l'aplicació del sistema de registre Harris-Lattes, la informatització integral del registre i, al meu entendre la més important, el disseny d'un ampli projecte de recerca interdisciplinària simultània (paleoecològica i paleoeconòmica), que es fonamentava en la implementació d'un protocol de recollida sistemàtica de mostres, d'acord amb les necessitats de cada disciplina. ${ }^{17}$ Jo mateix vaig valorar ja fa temps (López 1991a) la novetat d'aquests aspectes i l'equip va donar a conèixer també els principis generals d'alguns d'ells (Garcés et al. 1991; Junyent, López, Oliver 1992), per la qual cosa no m’estendré ara en aquest tema.

\section{Investigant la difusió}

La segona aportació, menys visible però amb moltes hores de treball darrere, és l'aplicació de les TIC a la difusió del patrimoni historicoarqueològic. En efecte, l'any 1996 l'Emili estableix contacte amb Jesús Lorés, llavors director del Grup de Recerca Interacció Humà Ordinador (GRIHO) del Departament d'Informàtica i Enginyeria Industrial de la UdL, i s'endega un procés de treball conjunt que malauradament es va interrompre arran de la mort inesperada d'aquest l'any 2006.

L'Emili sempre ha tingut dificultat amb el maneig dels ordinadors (ho sento, però ho havia de dir), però també ha tingut sempre molt clar el que voldria que fessin. I llavors un dels temes que li preocupaven era poder dotar la fortalesa del volum necessari per fer-la comprensible, tant sobre el terreny com - i aquesta era la novetat- de manera virtual. El Jesús Lorés crec que no havia treballat mai amb el patrimoni arqueològic, però la idea el seduí i es bolcà de forma desinteressada i generosa en l'empresa.

Durant la dècada dels noranta el debat sobre la funció social de l'arqueologia, la conservació i restauració, els models de presentació dels jaciments al públic i la difusió dels resultats estava plenament actiu a tot l'Estat (Ruiz Zapatero 1998). L'ús de les restitucions en 3D i la infografia en general tot just començava i el que estava de moda eren les recreacions en 3D, eina que als Vilars també s'havia utilitzat de la mà de dibuixants com Francesc Xavier Hernàndez o Francesc Riart.

Amb rigorós respecte vers les planimetries, als Vilars s'havia efectuat un primer tempteig de restitució virtual amb la publicació d'un CD de 6" (GIP - GRIHO 1998), que ara provoca un somriure, però també es planificà un projecte més ambiciós i completament innovador, almenys a casa nostra (figura 6.1). Es tractava de convertir la realitat virtual en una eina, no sols de difusió, sinó també de recerca: la realitat virtual com a extensió del registre arqueològic (Alonso et al. 2000b). L'objectiu era crear una base de dades

17. Un projecte similar de recerca interdisciplinària, utilitzant també el mètode d'excavació en extensió i el sistema de registre Harris-Lattes, es va endegar simultàniament l'any 1987 a l'Illa d'en Reixac (Ullastret, Baix Empordà), en l'excavació dirigida per M. Aurora Martín i Enriqueta Pons (López 1991b; Buxó et al. 1992).
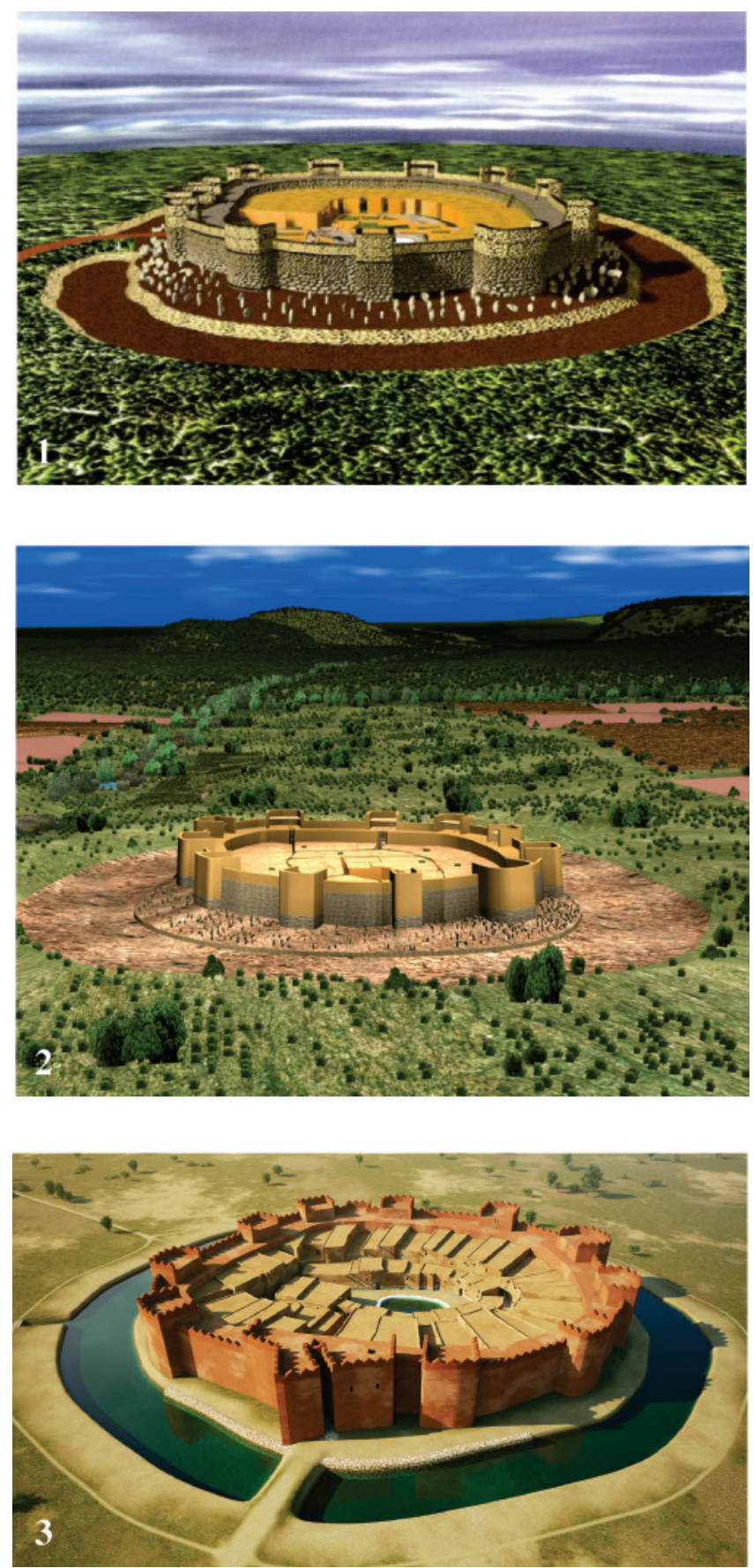

Figura 6. Evolució de les restitucions virtuals del jaciment: 1. (GIP-GRIHO 1998); 2. (GIP-GRIHO 2005); 3. (GIP- J. R. Casals 2016).

d'objectes tridimensionals que permetés representar de manera automàtica les planimetries $2 \mathrm{D}$ amb una interface que, a més a més, possibilités la representació a partir de variables com la cronologia o la ubicació espacial. El sistema de registre, orientat a fets arqueològics, estava preparat per al repte, però evidentment es feia necessària una tasca de programació ex novo i una infraestructura informàtica (software especialment) que el mercat no havia previst.

El projecte no va reeixir completament, però es donaren alguns passos en aquesta direcció com la restitució de la topografia antiga incorporant elements de paisatge en un segon vídeo i CD (GIP, GRIHO 2001; 2005), que també suposava un avanç 
i una novetat respecte a les aplicacions existents (figura 6.2).

En aquest context i comptant amb tota la feina feta, s'endegà encara un nou projecte consistent en el disseny d'una visita al jaciment amb la tecnologia de la realitat augmentada, una altra eina que llavors era també completament innovadora. Es tractava de dissenyar un sistema interactiu basat en el Model de Procés Centrat en l'Usuari o DUTCH Model (Designing for Users and Tasks from Concepts to Handles), que permetia combinar el món real amb el virtual segons el perfil de l'usuari i que es desenvolupava seguint un circuit predefinit dins del jaciment amb diferents punts d'observació. El projecte va ser presentat en els principals congressos d'arreu d'Europa i Amèrica sobre les CAA (Computer Applications in Archaeology) i HCI (Human Computer Interaction) ${ }^{18}$ i va implementar-se un prototipus sobre tauleta PC, que també fou sotmès a avaluacions tipus Focus Group per part dels ususaris (Vidal et al. 2007). En línies generals, els diferents tipus de públic van gaudir de la visita però es va fer evident la necessitat d'una major transparència del sistema i major adaptabilitat a determinats sectors com els infants, així com la poca operativitat de les tauletes existents en el mercat, massa feixugues i poc aptes per ser utilitzades en espais oberts. ${ }^{19}$

El projecte es va aturar, però recentment ha pogut rependre's sota paràmeres conceptuals diferents amb una app per a telèfons mòbils, que permet una visita al jaciment on l'espectador accedeix a imatges virtuals renovades (figura 6.3) i explicacions escrites o orals dels punts que visita, segons les seves preferències. Aquest recurs es va incorporar l'any 2017 i es pot descarregar des de qualsevol dispositiu mòbil o tauleta a Play Store (Android) o App Store (iOS), cercant per "Vilars d'Arbeca". ${ }^{20}$ És evident que ara ja no constitueix cap novetat, però continua palesant la voluntat de l'equip de mantenir-se al dia respecte qualsevol novetat relacionada amb la difusió del coneixement.

\section{El Grup d'Investigació Prehistòrica (GIP)}

La veritat és que no recordo quin any vam decidir constituir-nos com a grup d'investigació, ni existeix cap acta fundacional d'aquest fet. Crec que va ser arran de l'obtenció del primer projecte homologat pel

18. Berkeley (EUA) (Aguiló, Lorés, Junyent 2001); Salamanca (Alonso el al. 2001); Patras (Grècia) (Balaguer et al. 2001); Rostock (Alemanya) (Granollers et al. 2002a); Leganés (Granollers et al. 2002b); Barcelona (Tartera et al. 2003).

19. Al llarg de tot aquest procés crec que és just fer constar la gran implicació en els diferents projectes d'Enric Tartera i Ares Vidal, llavors becaris predoctorals de l'Emili (2002-2006 i 2003-2007, respectivament).

20. El projecte es va endegar l'any 2016 en el marc de la FECYT: "La Ciència no s'aprèn a la xarxa. Apropar el mètode científic a les aules de secundària”, que desenvolupava el grup de recerca "Didàctica de la Història, la Geografia i altres Ciències Socials (DHiGECS)" de la Universitat de Barcelona (IP: Dr. Joan Santacana). Els continguts científics els va aportar el GIP, la conceptualització i disseny el DHiGECS, i el desenvolupament de l'app, l'empresa Develoop Sotfware. Les noves restitucions virtuals les va dur a terme Josep Ramon Casals.
Ministerio de Educación y Ciencia l'any 1992, però, en qualsevol cas, des de l'endegament del projecte de recerca als Vilars l'any 1987, la direcció s'efectuava en equip i s'actuava com a equip, independentment de la posició acadèmica dels seus membres, llavors l'Emili, l'Ignasi Garcés, l’Ángel Lafuente i jo mateix.

Per liderar un grup no n'hi ha prou amb tenir més experiència o més coneixements que la resta, cal també saber "gestionar" les persones i sobretot saber establir els mecanismes que facilitin la seva cohesió interna: que els seus components s'hi identifiquin i se sentin partícips tant de la direcció estratègica com en el dia a dia. L'Emili tenia molt clar això, així com la convicció, gens trivial, que els articles se signarien col-lectivament i per estricte ordre alfabètic. Si observeu la bibliografia adjunta en aquest homenatge, podreu comprovar com el seu nom queda molt sovint diluït enmig de llarges llistes d'autors, quan per aclamació i de facto ell era l'investigador principal del grup. No sempre és aquesta la pràctica habitual en els mitjans acadèmics i menys ara que el mateix sistema ha imposat la competència individual i els currículums personals per damunt del funcionament cooperatiu dels equips de recerca.

El GIP va continuar creixent amb entrades i sortides de persones diferents, perquè l'únic requisit per formar-ne part era implicar-se i treballar en el projecte, decisió absolutament personal, tant del personal vinculat a la UdL com del que per raons diverses havia perdut aquest lligam. Per desgràcia, l'equip no va poder assolir mai una captació de recursos estable i retenir molts investigadors/es que van haver de cercar la seva subsistència per altres mitjans. En qualsevol cas, els Vilars i altres projectes van esdevenir una escola d'excavació per a estudiants de tot el país i també han estat una escola de direcció per als que han volgut anar una mica més enllà (figura 7).

El grup s'acollia a totes les convocatòries de subvencions del Departament de Cultura, però també, des del 1992 fins l'any 2015, va gaudir de sis projectes consecutius homologats pel Ministerio de Educación y Ciencia, tots ells — tot i la direcció col-lectiva- amb l'Emili com a IP:

- PB92-0148, Primera Edad del Hierro y Época Ibérica
en la Catalunya occidental. Territorio y asentamientos

- PB96-0419, Un modelo singular de la transformación de las sociedades segmentarias en sociedades complejas: el Valle del Segre (II-Ier milenio ANE)

- BS02001-0523, De la aldea a la ciuitas. Materialidad e ideología: contrastación de modelos en el noroeste del Mediterráneo. II y I milenios ANE

- HUM2005-06384/Hist, Las transformaciones sociales a través de los espacios de la vida y la muerte en el noroeste del Mediterráneo durante el II y I milenios ANE

- HAR2008-05256, La arquitectura del poder en el Valle del Segre y el Mediterráneo noroccidental durante el III $y$ el I milenio A.N.E.

- HAR2012-36877, Producción, consumo y poder en el valle del Segre y en el Mediterráneo noroocidental durante el III y el I milenio A.N.E.

En aquests projectes, els Vilars i a partir de 1996 Minferri (Juneda, les Garrigues) constituïen els vai- 


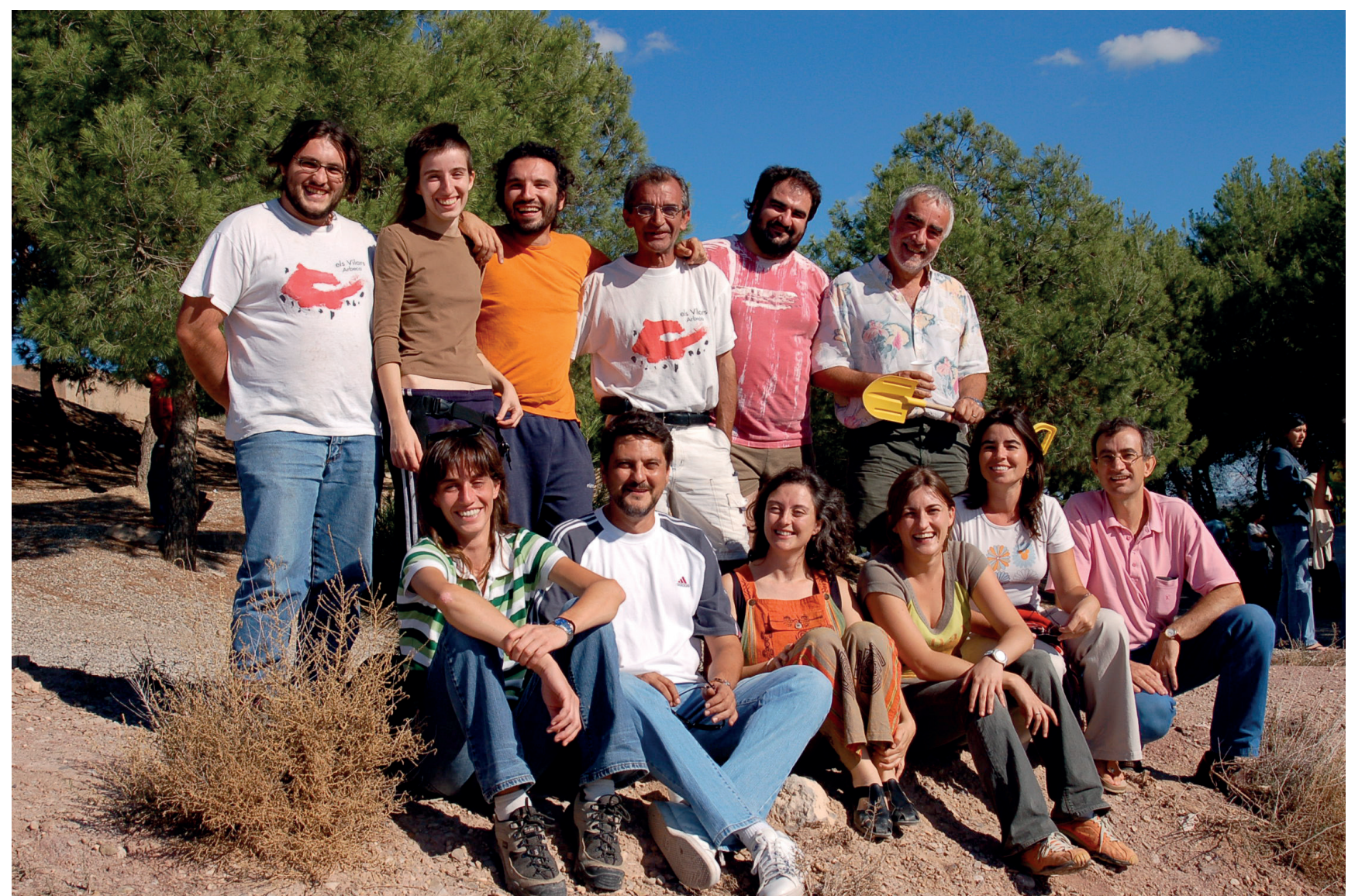

Figura 7. L'equip del GIP amb l'Ignasi Garcés durant la festa del 20è aniversari de les excavacions als Vilars l'any 2005. D'esquerra a dreta, drets: Òscar Escala, Ariadna Nieto, Andreu Moya, Joan B. López, Enric Tartera i Emili Junyent; asseguts: Anna Colet, Ángel Lafuente, Natàlia Alonso, Ares Vidal, Montse Gené i Ignasi Garcés.

xells insígnia de la recerca. Ben aviat, però, s'amplià l'horitzó cronològic de la investigació (III - I mil.lenni ANE) i el marc geogràfic (el Mediterrani occidental). Les pràctiques econòmiques, les transformacions socials, la ideologia... constituïen els àmbits de recerca d'un discurs que s'articulava entorn de l'explicació de l'emergència del poder i les seves diferents manifestacions. Per dur-ho a terme, es comptava amb un ampli equip de col-laboradors d'equips catalans i estrangers, ${ }^{21}$ especialistes en matèries diverses, als quals cal reconèixer la seva contribució a la consolidació del propi equip i al reconeixement obtingut en el si de la comunitat científica.

D'altra banda, per poder desenvolupar-los el GIP va assumir altres projectes, finançats tant per l'Administració

21. Esmentaré només els més assidus, com la Bibiana Agustí (In Situ S.C.P. - antropologia), el Josep Lluís Ribes (Institut d'Estudis Ilerdencs - difusió), el Josep Gallart (SS.TT. de Cultura de Lleida) i la Carme Rovira (Museu d'Arqueologia de Catalunya - arqueometal-lúrgia), la Rosa M. Poch i el Carles Balasch (Departament de Medi Ambient i Ciències del Sòl de la Universitat de Lleida - geomorfologia, edafologia), el Santi Riera (Universitat de Barcelona - palinologia), la Mercè Bergadà (Universitat de Barcelona - micromorfologia), la Raquel Piqué (Universitat Autònoma de Barcelona - antracologia), el Dominique Garcia (Université d'Aix-Marseille - urbanisme) o l'Armelle Gardeisen (UMR 5140 del CNRS - arqueofauna). com per l'empresa privada, ${ }^{22}$ la direcció dels quals mai va voler assumir personalment, la qual cosa vam fer l'Ángel Lafuente, la Natàlia Alonso o jo mateix. Crec que també és just manifestar, però, que sempre vam comptar amb el seu suport i assessorament.

En aquest context, una altra iniciativa, que penso que cal enaltir per l'esforç que suposava, va ser compaginar la temàtica parcial o global d'aquests projectes amb l'organització de reunions científiques i workshops que constituien un escenari perfecte per a la posada en comú de les investigacions en curs o per rebre les aportacions d'altres equips. Les diferents comunicacions, d'altra banda, es publicaven immediatament a la Revista d'Arqueologia de Ponent

22. Entre els més significatius, l'excavació del Vilot de Montagut (Lleida) (Alonso et al. 2002) i Minferri (Juneda, les Garrigues) (Equip Minferri 1997) arran de la construcció del Tren d'Alta Velocitat (AVE); l'excavació generada per la construcció del canal Segarra-Garrigues de les estàtues-menhir i el dolmen dels Reguers de Seró (Artesa de Segre, la Noguera) (López, Moya, Martínez 2015), posteriorment traslladades a un museu monogràfic construït ex professo i objecte de valoracions contraposades (Junyent 2015b); l'excavació de la Cova de Montanisell (Sallent-Coll de Nargó, Alt Urgell) (Armentano et al. 2008), coordinada pel Museu d'Arqueologia de Catalunya, o l'excavació del poblat de Vincamet (Fraga, Osca) (Moya et al. 2005), codirigida amb la Dirección General de Aragón (Javier Rey) i finançada per la UTE Fraga. 
i constitueixen encara ara referències de rabiosa actualitat en les seves respectives temàtiques.

Destacaré la reunió celebrada a la Universitat de Lleida i Arbeca l'any 2003 sobre Chevaux-de-frise i fortificació en la primera edat del ferro europea, la qual va suposar la posada al dia amb investigadors nacionals i europeus d'una problemàtica que no havia estat abordada des dels treballs de P. Harbison als anys setanta (Harbison 1971; 1979) i que va possibilitar la publicació d'un volum (Alonso et al. 2003) que restarà vigent durant molts anys com l'estat de la qüestió sobre el tema. ${ }^{23}$

\section{Una producció científica diversificada}

No voldria acabar aquest apartat sense un comentari general sobre les seves publicacions. He pogut recollir un total de 177 treballs, entre ells 15 llibres i la resta són articles apareguts en les principals revistes de l'àmbit català i estatal (63) o en obres col-lectives, generalment actes de congressos nacionals i internacionals (84). La major part —alguns els he anat citant - estan relacionats amb la investigació, però he de destacar altres facetes de la seva activitat difusora com les contribucions en revistes i obres generals de divulgació (infra), o articles d'opinió sobre temes relacionats amb la recerca o amb la política arqueològica i universitària, els quals realitzava tant de manera individual (Junyent 1989; 1993; 1999; 2000; 2009; 2010) com col-lectiva (MARC-7 1991; Rafel, Junyent, Alonso 2017). Personalment crec que la historiografia de l'arqueologia catalana publicada en la revista L'Avenç (MARC-7 1986a; 1986b; 1986c) constitueix una visió crítica sobre el context social i polític que va acompanyar la formació i el desenvolupament de l'arqueologia a casa nostra que penso que no ha estat mai plantejada en cap altra publicació. ${ }^{24}$

Igualment del màxim interès han estat les 15 ressenyes sobre diferents llibres, publicades principalment a la Revista d'Arqueologia de Ponent (Junyent 2009a; 2009b; 2010; 2011; 2012; 2013; 2015; 2016; 2017); Trabajos de Prehistoria (Junyent 2008; 2014); Pyrenae (1972; 1973a; 1973b) o L'Avenc (Junyent 1987); totes elles estan caracteritzades per la seva exhaustivitat i valoració crítica de l'obra analitzada.

Tot plegat, i no incloc les desenes d'articles publicats en la premsa local, palesa que, més enllà d'una tasca constant de producció científica, hi ha el compromís de la seva persona amb l'entorn social que

23. La primera reunió es va celebrar l'any 1995 en el marc del — ja esmentat- XVIII Curset d'Arqueologia: Datació radiocàrbonica i calibratge (Junyent, López, Martín 1995); després, l'any 2003, la reunió acabada d'esmentar sobre els Chevauxde-frise i darrerament els workshops:

-Portes i sistemes d'accés en les fortificacions protohistòriques del Mediterrani occidental (Universitat de Lleida, 2008) (Junyent, López 2009).

- Les defenses exteriors i la poliorcètica mediterrània preromana: els fossats, segles VII a III a.n.e. (Universitat de Lleida 2010) (Junyent, López, Mastria 2011a).

- Reunió Internacional: Molins i mòlta al Mediterrani occidental durant l'edat del ferro (Arbeca-Universitat de Lleida. 2013) (Alonso 2014).

24. Signaven aquests articles: Xavier Dupré, Oriol Granados, Xavier Nieto, Núria Rafel, Francesc Tarrats i ell mateix. l'envolta, la defensa d'unes conviccions i la voluntat de contribuir al canvi.

\section{Gestió del patrimoni, difusió de la recerca i socialització del coneixement}

A més de la seva implicació en el desenvolupament de la Universitat de Lleida, la seva participació i col-laboració en les tasques relacionades amb la política general de promoció i gestió del patrimoni cultural català, especialment l'arqueològic, ha estat contínua. D’aquesta manera, l'any 1981, el seu reconegut prestigi científic li valgué el nomenament com a membre de la Comissió Assessora del llavors recentment creat Servei d'Arqueologia (DOGC núm. 109 de 28 de gener de 1981) i del Consell del Patrimoni Cultural de Catalunya (Decret 188/1981, de 10 de juliol). L'any 1986 fou també nomenat membre del Consell Permanent de la Fundació Pública Institut d'Estudis Ilerdencs de la Diputació de Lleida.

Entre 1987 i 1993 fou membre també de la Comissió Tècnica del Patrimoni Cultural de Catalunya als SS.TT. del Departament de Cultura de la Generalitat de Catalunya de Lleida i, des de la seva creació l'any 1999 fins ara, membre de la Comissió Assessora del projecte sobre la Ruta dels Ibers del Museu d'Arqueologia de Catalunya. Més recentment (2008-2009), ha format part del Consell Assessor del Pla Integral d'Arqueologia de Catalunya (PIACAT) i, amb la implementació d'aquest pla, fou nomenat l'any 2011 vocal de la Comissió de Recerca d'Arqueologia i Paleontologia en representació de la Universitat de Lleida. Finalment, des del 25 de setembre de 2012 fins a la seva jubilació ha estat membre del Consell de Direcció de l'Institut Català d'Arqueologia Clàssica (ICAC) en representació del Consell Interuniversitari de Catalunya.

Puntualment ha desenvolupat altres activitats com la d'expert avaluador del Plan Nacional I+D+I, convocatòria 2009, nomenat per la Dirección General de Programas y Transferencia de Conocimiento del Ministerio de Ciencia e Innovación, o ha col-laborat, quan l'hi han requerit, amb els museus locals com el Museu Comarcal de la Noguera en qualitat de membre del Patronat del Museu (1983) o amb el Musée de Cerdagne a Saillagouse (França) com a membre del Comitè Científic (1998).

La difusió social de la recerca o, com ell sempre ha preferit anomenar-la, "la socialització del coneixement" ha estat un dels principis rectors de la seva activitat quotidiana que, a més a més, ha sabut traslladar a la resta de l'equip. Les activitats desenvolupades en aquest sentit són incomptables i el recull que presento té un valor il.lustratiu.

D'una banda, des de l'inici de la seva carrera, va col-laborar en la redacció d'enciclopèdies i obres generals de les més importants editorials del país. En són una prova les seves aportacions a la Historia Antigua y Medieval de l'Editorial Planeta (Junyent 1974; Junyent, Martí 1974), la Història de Catalunya de l'Editorial Salvat (Junyent 1978a) o el Diccionari d'Història de Catalunya (Junyent 1992), l'Atles d'Història de Catalunya (Junyent 1995) i la Història Mundial de 
Catalunya (Junyent 2018), totes d'Edicions 62. Les seves aportacions més significatives en aquest sentit han estat, però, la direcció i redacció parcial del primer volum: Els temps prehistòrics $i$ antics. Fins al segle $V$ (Junyent 1996) de la gran obra dirigida per Borja de Riquer i editada per Enciclopèdia Catalana: Història, Politica, Societat i Cultura als Pä̈sos catalans, o també la redacció, juntament amb l'Arturo Pérez, del primer volum de la Història de Lleida, editada per Pagès Editors: L'antiguitat, d'Iltirta a Ilerda (Junyent, Pérez 2003).

D'una altra banda, ha col-laborat en els consells assessors o de redacció tant de revistes adreçades al gran públic com L'Avenç (des de 1979) o Sàpiens (des del 2002), com en revistes especialitzades: Trabajos de Prehistoria (des de 1997) o Cypsela (1998-2003 i 2009-). Evidentment, és membre del consell de redacció de la Revista d'Arqueologia de Ponent des de la seva fundació l'any 1991.

Ha impartit nombroses conferències arreu del país i, juntament amb Natàlia Alonso i jo mateix, ha vetllat per sensibilitzar el públic de l'entorn immediat de Lleida organitzant cicles com La Guerra a l'Antiguitat (Ateneu Popular de Lleida, 2005) o les Setmanes de la Prehistòria (2006-2014), ${ }^{25}$ realitzades a la Biblioteca Pública i Arxiu Històric de Lleida.

El muntatge d'exposicions, com a eina divulgativa, ha estat una altra de les activitats en les quals s'ha esmerçat profundament, especialment en els darrers anys de la seva carrera. ${ }^{26}$ Les més significatives estan relacionades amb els Vilars i són, sens dubte: Cavalls $i$ poder en el món ibèric, ${ }^{27}$ una exposició que des del 2009 es passeja per tot Catalunya i es va presentar fins i tot l'any 2012 a l'Espai Van Gogh d'Arles i a la Universitat Paul Valéry de Montpeller (figura 8), i La Fortalesa dels Vilars d'Arbeca. Terra, aigua $i$ poder en el món ibèric, ${ }^{28}$ presentada primer al Museu de Lleida (2016) i després a la Sala la República d'Arbeca (2016) i al Museu d'Arqueologia de Catalunya de Barcelona (2017). Aquesta darrera, guardonada amb el Premi Musa de la revista Auriga 2017, commemorava els trenta anys d'excavacions als Vilars i s'acompanyà amb l'edició per part del Museu de Lleida del respectiu catàleg (Junyent, López 2016).

25. 1a. 2006: Els primers humans: visions alternatives.

2a. 2007: L'art rupestre. 100 anys després del descobriment del Cogul.

3a. 2008: Origen $i$ difusió de l'agricultura.

4a. 2009: El megalitisme.

5a. 2010: L'edat del bronze: mosaic de cultures.

6a. 2011: La violència a la prehistòria.

7a. 2012: L'origen de les desigualtats socials.

8a. 2013: L'alimentació a la Prehistòria.

9a. 2014: Les joies a la Prehistòria.

26. L'any 1987, després de la intervenció a Gebut, ja va organitzar una primera exposició fotogràfica: Gebut: la imatge d'un poblat ilerget, presentada a l'IEI. S'hi recollia, a més de fotos antigues i actuals del jaciment i els seus materials, el treball del fotògraf Òscar Ribes: Metamorfosis.

27. L'exposició va ser organitzada pel GIP de la Universitat de Lleida i la Fundació Pública Institut d'Estudis Ilerdencs de la Diputació de Lleida. Actuaven com a comissaris: Emili Junyent, Joan B. López, Ariadna Nieto i Josep Lluís Ribes.

28. L'exposició fou organitzada pel Museu de Lleida, la Diputació de Lleida (IEI) i la Universitat de Lleida (GIP). Actuaren com a comissaris: Emili Junyent i Joan B. López.

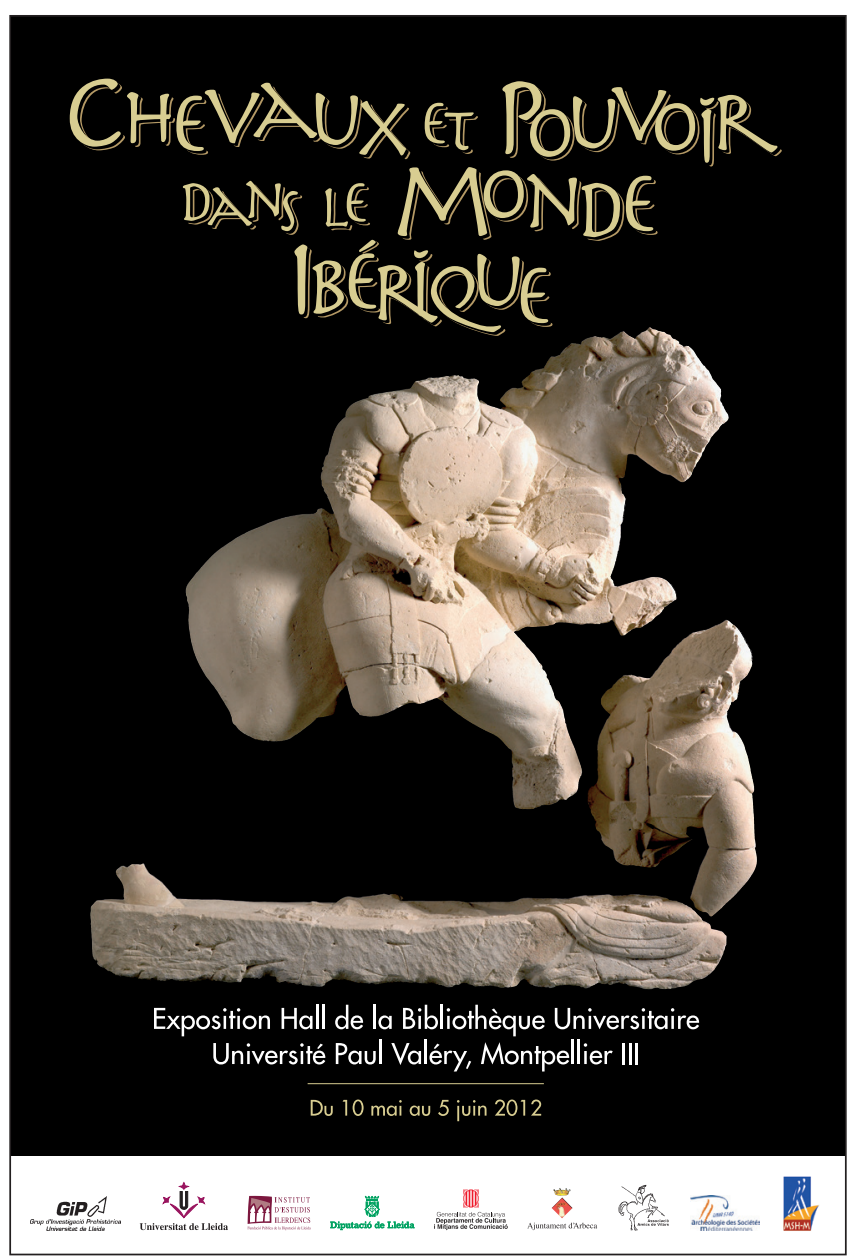

Figura 8. Cartell de la presentació de l'exposició a Montpeller.

Ha de constituir, d'altra banda, l'embrió d'un futur museu monogràfic sobre el jaciment.

Ha format part també, però, del comissariat d'altres exposicions no menys valuoses, però més efímeres, com: 25 anys d'excavacions arqueològiques a la Fortalesa dels Vilars (Arbeca, les Garrigues), presentada a la Fira de l'Oli de les Borges Blanques l'any 2010; El molí rotatiu: una gran revolució tecnològica ibèrica, presentada al jaciment dels Vilars l'any 2011; Dones de la plana... Dones de la muntanya, presentada l'any 2014 al jaciment dels Vilars, després a la Biblioteca Pública Sant Agustí de la Seu d’Urgell (2015), a la Biblioteca Pública Joan Maluquer i Viladot d'Artesa de Segre (2016) i actualment al Centre d'Interpretació de les pintures rupestres de la Roca dels Moros del Cogul; i més recentement (2018): Vilars: La fortalesa de l'Aigua, presentada a la fortalesa dels Vilars, amb motiu del 18è Cap de Setmana Ibèric. No cal dir que ha col-laborat en la resta d'exposicions que ha organitzat el GIP. ${ }^{29}$

29. Esmento com a més significatives: Colors de terra. Minferri. La vida i la mort en una aldea d'ara fa 4000 anys (2001-2018); L'origen de l'olivera (2005-2018) o Escultures mil.lenàries (20092012). 


\section{La fortalesa dels Vilars: un llegat per al futur}

Aquest títol de paràgraf no és meu i tampoc recordo on l'he vist o sentit per primera vegada, però és el més adient per sintetitzar una part de la tasca desenvolupada per l'Emili al llarg de trenta-quatre anys. No sé quants jaciments hi ha a Catalunya o arreu de l'Estat espanyol que, ignorats per la Història sota terra, són de cop i volta descoberts i en el que dura la vida professional d'un investigador/a esdevenen no sols un referent científic, sinó també una icona patrimonial d'abast nacional i internacional. Els Vilars ho és i el mèrit principal és de l'Emili.

És evident que no ha dut a terme aquesta tasca tot sol i que ha comptat —com hem vist— amb el suport d'un ampli equip darrere, però puc assegurar que, pel que respecta a la recuperació i posada en valor patrimonial del jaciment, és ell qui hi ha invertit més hores i esforços i, a més a més, ho ha fet seguint un full de ruta perfectament racionalitzat i sistematitzat, que va tenir molt clar des que a mitjan anys noranta es va poder posar al descobert la planta sencera del jaciment i veure'n l'estat de conservació.

La primera fita fou la declaració del jaciment com a Bé Cultural d'Interès Nacional (BCIN) en la categoria de Zona Arqueològica, fet que s'aconseguiria l'any 1998 (DOGC número 2673 de 98/07/03). La segona, l'any 2001, la redacció del Pla Director Vilars 2000. Projecte d'excavació arqueològica, ordenació, consolidació i restauració de la Fortalesa dels Vilars d'Arbeca (les Garrigues, Lleida), l'eina que hauria de regir el futur a curt i mitjà termini del jaciment. La tercera (2010-2011), amb la implementació del pla, l'obertura del jaciment al públic, la qual va comportar un nou arranjament dels accessos, el tancament del recinte, una intensa tasca de consolidació i restauració interior, l'arranjament d'un circuit intern per a les visites amb punts d'informació, passarel-la damunt la rampa del fossat, escala per sortejar el testimoni, passeres amb peces mòbils als carrers... i fins i tot la il-luminació per a vistes nocturnes.

L'Emili supervisava personalment totes aquestes tasques, vetllant perquè es complissin escrupolosament els principis rectors establerts en el Pla Director, especialment que en la restauració es respectés l'estratigrafia arquitectònica, fins al punt que en més d'una ocasió va fer desmuntar trams de mur o muralla que ja estaven restaurats.

No obstant això, el desenvolupament del conjunt d'aquest procés no va ser tan lineal com explico i sí molt més complex, ${ }^{30}$ però el que vull remarcar és que per fer-lo possible darrere hi ha centenars, potser milers d'hores "perdudes" redactant informes i projectes, sol-licitant subvencions, reunions i entrevistes amb els responsables de les diferents administracions..., unes hores que no sempre són fructuoses i que, a més a més, tots sabem que no comptabilitzen en el currículum personal.

30. Renuncio a estendre'm en aquest apartat perquè també l'hem detallat recentment en diferents publicacions (Junyent 2014; Junyent, López 2016)
Per part del GIP, ja ho he dit, aquesta tasca la va dur a terme sempre ell personalment ${ }^{31} \mathrm{i}$ puc afirmar també que va trucar a totes les portes existents, des dels ens locals: Ajuntament d'Arbeca, Consell Comarcal de les Garrigues, Consell Comarcal del Segrià, Fundació Pública Institut d'Estudis Ilerdencs i Diputació de Lleida, Universitat de Lleida..., fins a l'administració autonòmica: Departament de Cultura, Departament del Treball, Departament d'Agricultura, Ramaderia i Pesca, i també l'administració estatal: Ministerio de Cultura, Ministerio de Fomento, Ministerio de Economía y Competitividad. Més d'un polític es recordarà de la seva persona i de la seva insistència.

Va cercar també el mecenatge de l'empresa privada: Caixa de Tarragona, Prefabricats Pujol SA, SCCL del Camp l'Arbequina, Fundació "la Caixa", amb les quals també va aconseguir col-laboracions puntuals. Potser l'única via en què no va (vam) aconseguir reeixir va ser la del finançament europeu directe, tot i que l'Ajuntament d'Arbeca va dur a terme diferents actuacions relacionades amb el jaciment, com - per exemple- l'asfaltat del camí d'accés amb fons FEDER cofinançats.

En qualsevol cas, totes aquestes institucions, no puc ara explicar-ho amb detall, han aportat quelcom al desenvolupament del projecte, però paradoxalment la inversió quantitativament més important (500.000 € d'un sol cop) va provenir del Ministerio de Cultura Instituto del Patrimonio Histórico Español (programa presupuestario 337B Conservación y Restauración de Bienes Culturales, capítulo 7), la qual es va obtenir gràcies a una esmena als pressupostos generals de l'estat del 2007, presentada al Senat pel Grup Entesa pel Progrés (PSC, ERC i IC-EUiA). Amb ella va ser possible l'excavació del fossat, sens dubte la intervenció que més ha contribuït a la monumentalització de la fortalesa.

En moltes d'aquestes negociacions he d'assenyalar també que va comptar des de l'inici amb la col-laboració, i en molts casos la iniciativa, dels diferents alcaldes d'Arbeca $^{32}$ que sempre han fet costat al projecte i han aportat els mitjans dels quals podien disposar (infraestructures, locals, peonatge...) per tirar-lo endavant. Però arribats en aquest punt, se'm fa necessari incidir en un aspecte que també sempre ha tingut molt clar: les relacions amb el poble d'Arbeca.

$\mathrm{Li}$ he sentit repetir moltes vegades una frase que al principi jo no copsava en tota la seva magnitud: "el jaciment no tirarà endavant si el poble d'Arbeca no se'l sent seu...”. Amb aquest convenciment, ben aviat (l'any 2000), amb la col-laboració de l'Institut de Ciències de l'Educado de la UdL, es va dur a terme una primera activitat: "Vilars ens descobreix la cultura ibèrica", adreçada als alumnes de primària $\mathrm{i}$ consistent en tallers i l'elaboració de materials didàctics

31. Molts d'aquests ajuts no es podien sol-licitar des de la Universitat i corresponia a l'Ajuntament d'Arbeca fer-ho. L'Emili preparava simplement la part arqueològica i pel que respecta a les tasques de restauració i consolidació col-laborava amb l'arquitecte municipal: la Carme Casals, amb qui fins i tot va publicar algun article (Junyent, Casals 2013).

32. L’Agustí Perelló, a l'inici; en Josep Pau, en Jaume Aixalà, en Santi Sans, la Ramona Barrufet i des de l'any 2007 en Joan Simó. 


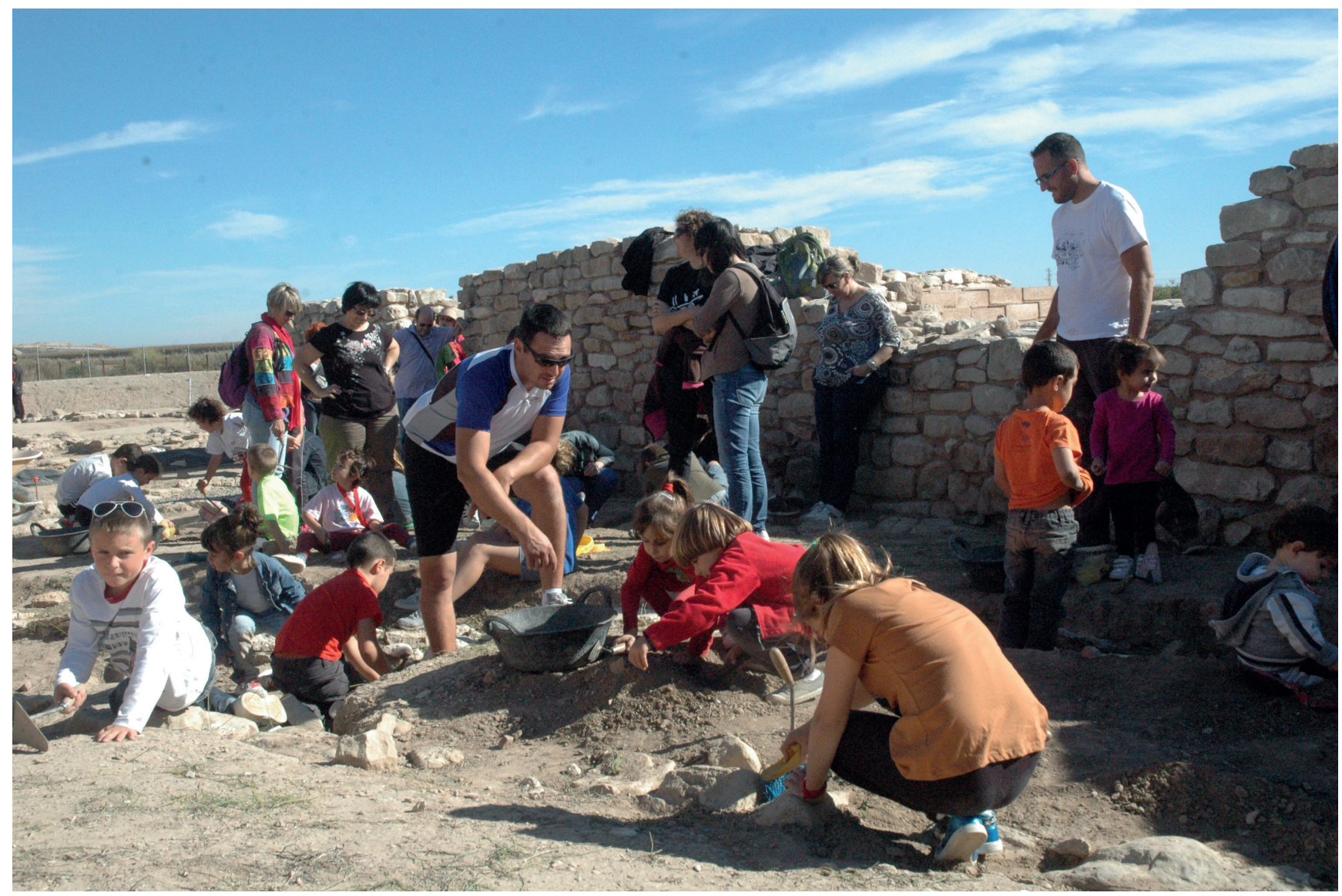

Figura 9. Taller d'excavació amb nens i i nenes d'Arbeca, l’any 2013.

específics, en la qual van participar més d'un centenar de nens de les escoles CEIP Albirka (Arbeca), CEIP Joan XXIII (les Borges Blanques) i ZER Riu Corb (Belianes). Després la iniciativa, malauradament, no ha tingut la continuïtat sistemàtica desitjada, però no hi ha dubte que era el camí més idoni per sensibilitzar l'entorn immediat vers el seu patrimoni (figura 9).

També ben aviat, va insistir en la necessitat de la creació d'una Associació d'Amics de Vilars i quan aquesta, de manera autònoma, es va constituir l'any 2005, no va dubtar a promoure una trobada d'associacions similars de la resta de l'Estat (Alonso et al. 2007), que pogués servir — tant per a ells com per al propi equip - de punt d'intercanvi d'experiències i d'orientació sobre les possibles línies d'actuació a seguir. L'associació, igual que va néixer, ha continuat caminant sola i mantenint unes relacions d'exquisida sintonia amb l'equip, que hem col-laborat en tot el que se'ns demanava, tallers d'excavació per a la gent del poble, visites guiades, una exposició, xerrades o organitzar conjuntament els Caps de Setmana Ibèrics, però les múltiples activitats que l'associació ha realitzat i realitza ${ }^{33}$ en el jaciment han estat clau

33. Algunes d'elles, com les "Nits del Foc" o els "Tast - Jazz", han esdevingut festes d'abast supracomarcal, que aglutinen cada any prop d'un miler de persones. Vegeu el ressò i l'ampli ventall d'activitats a la web de l'Associació: <http://www.amicsdevilars. $\mathrm{com} />$. perquè molts sectors del poble d'Arbeca gradualment s'identifiquessin amb la fortalesa dels Vilars i la consideressin una icona del seu passat ancestral. Especialment significativa de la sintonia entre l'equip i el poble fou la participació multitudinària en el dinar de germanor commemoratiu dels vint anys de recerca al jaciment, celebrat l'any 2005 a l'espai de la capella de Sant Miquel de les Borgetes (figura 10).

Hi ha una altra estratègia de difusió que l'Emili ha vetllat especialment: la presència en els mitjans de comunicació i l'actualització de la informació a través d'internet i les xarxes socials. En aquest sentit, l'any 1999, els Vilars ja disposava d'un primer web site (http://www.vilars2000.com), una eina que llavors encara molt pocs jaciments utilitzaven i que ell va concebre com una plataforma interactiva portadora del dia a dia del jaciment i les activitats del grup; el web després es renovà (2012) amb una versió més moderna (http://www.vilars.cat/).

Sigui com sigui, la implicació en la vida social del poble va tenir un retorn i durant la festa major de l'any 1998, l'Emili va ser elegit pregoner. Posteriorment, quan després del buidament del fossat i l'avançament dels treballs de restauració es podia contemplar la fortalesa com un conjunt monumental de primera magnitud, va ser nomenat "fill adoptiu de la vila d'Arbeca" per decisió unànim del Ple de la Corporació Municipal del 14 d'abril de 2008. El document oficial li va ser lliurat públicament el 30 


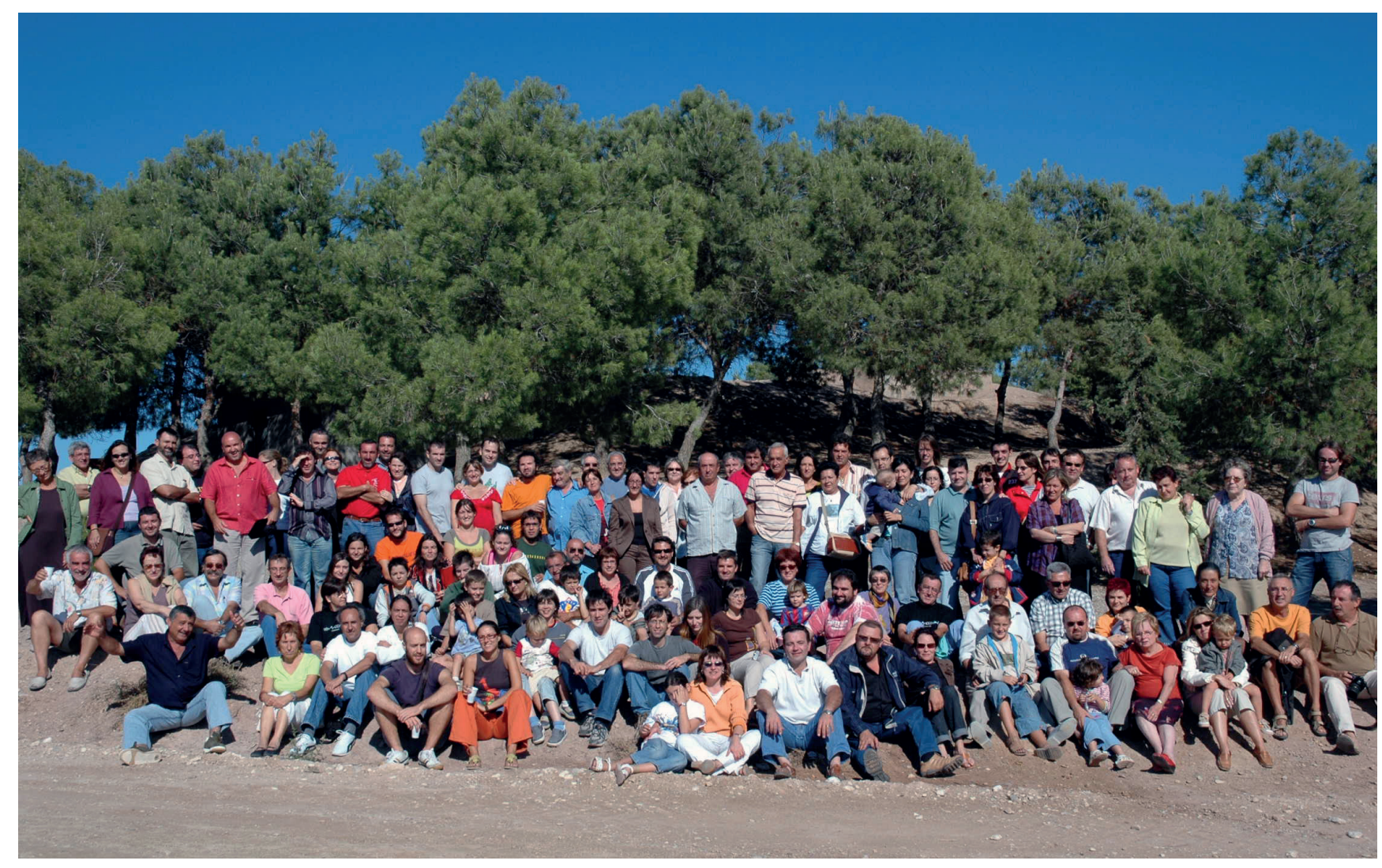

Figura 10. Participants en la festa commemorativa del 20è aniversari de les excavacions als Vilars, l'any 2005.

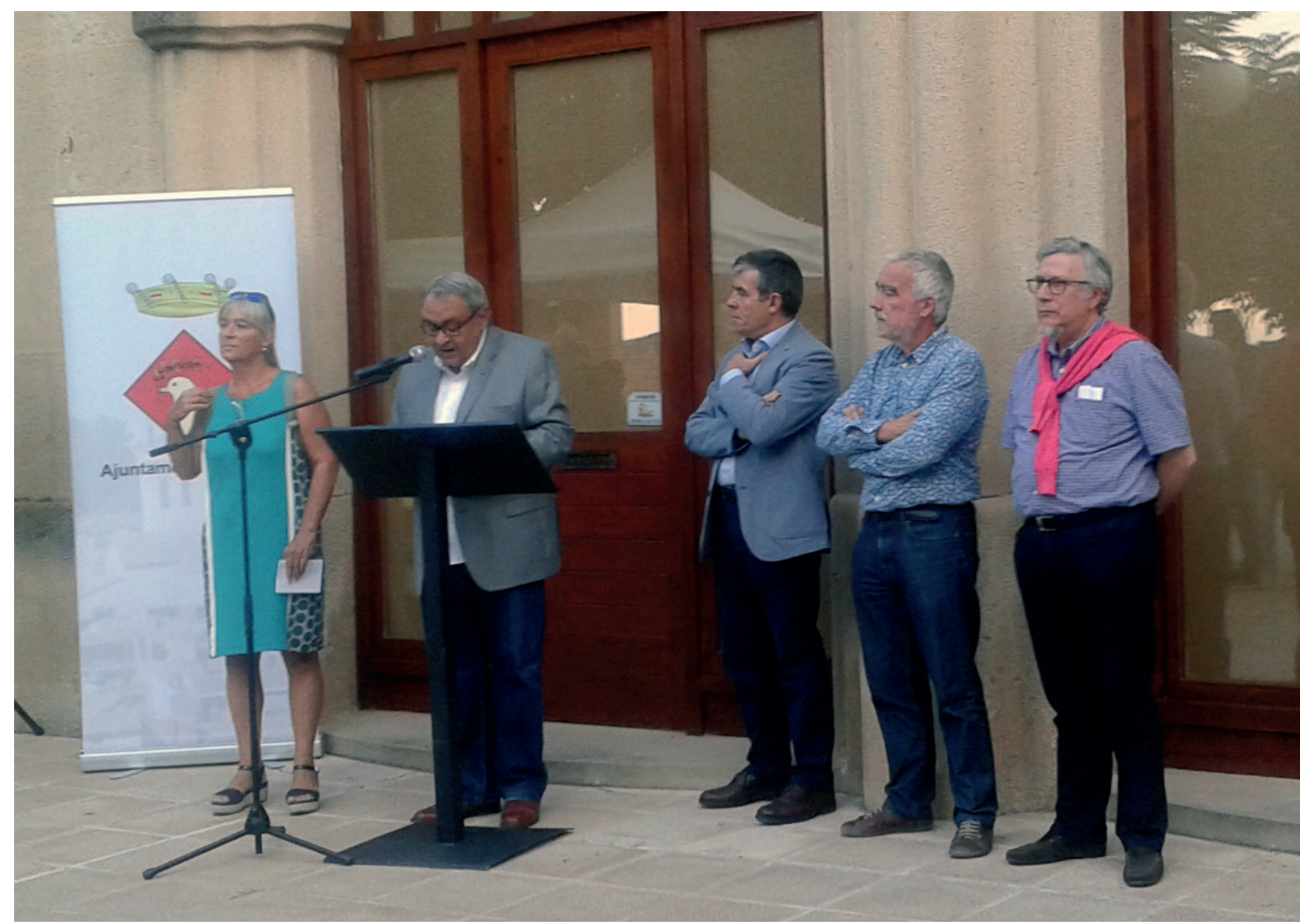

Figura 11. L'alcalde d'Arbeca, Joan Simó, en l'acte d'entrega de l'acta municipal nomenant "Fill adoptiu d'Arbeca" l'Emili Junyent (16/08/2016). A la seva dreta, Montse Macià (Directora de l'IEI); a l'esquerra, Josep Giralt (director del Museu de

Lleida), l'Emili i Josep Borrell (director dels Serveis Territorials de Cultura de la Generalitat de Catalunya de Lleida). 


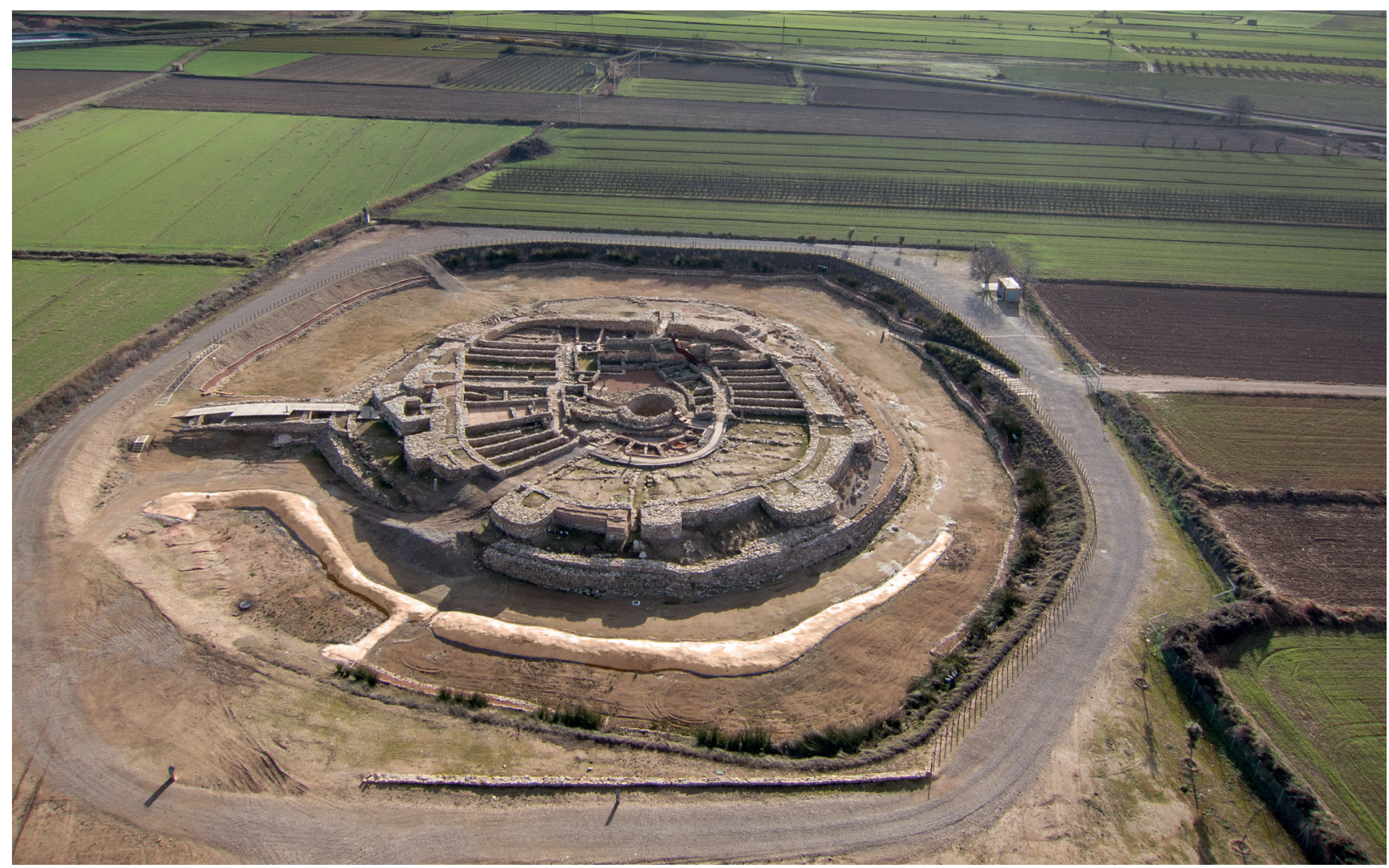

Figura 12. Vista general de la fortalesa dels Vilars, l'any 2014.

de setembre de 2016, en l'acte de la presentació a Arbeca de l'exposició ja esmentada: La Fortalesa dels Vilars d'Arbeca. Terra, aigua i poder en el món ibèric. L'exposició, d'altra banda, ell l'havia dedicat públicament al poble d'Arbeca en la seva presentació al Museu de Lleida l'any anterior; el sentiment mutu de gratitud es manifestava en perfecta simbiosi i no mancaren mostres d'emoció continguda (figura 11).

En qualsevol cas, la fortalesa dels Vilars avui s'alça amb serena majestuositat enmig dels camps de conreus de les Garrigues i allí seguirà per sempre més (figura 12). Rep una mitjana de 7.000 visites anuals, apareix en els manuals escolars, va quedar en segon lloc en el concurs "Monument favorit dels catalans" de l'any 2017 amb 54.322 vots, i la seva fama ha traspassat tant l'Ebre com els Pirineus. Els mitjans de comunicació catalans i de l'Estat espanyol se n'han fet ressò en els darres anys ${ }^{34} \mathrm{i}$ és present al Museu d'Interès Nacional de Lleida, al Museu d'Arqueologia de Catalunya, al Museo Arqueológico Nacional de Madrid, on apareix en l'audiovisual de presentació, i en la remodelada sala de El Carambolo al Museo Arqueológico de Sevilla.

Resta encara coses per fer, és cert. Una d'elles, la més senzilla, finalitzar l'excavació a l'interior i en determinats punts fora muralla; la rapidesa de la seva execució només depèn dels mitjans econòmics que es

34. Esmentaré entre els més populars els programes monogràfics Sota Terra, emès per TV3 l'any 2010; els quatre documentals del programa La Aventura del Saber, sèrie El túnel del tiempo, emesos per TV2 l'any 2016, o el documental emès també per aquesta cadena l'any 2018 en el programa Arqueomania, que dirigeix Manuel Pimentel. puguin assolir durant els propers quatre anys. L'altra, no menys important, mantenir viu el monument. La tercera no sé si serà mai factible i aquest crec que és l'únic projecte que l'Emili no ha reexit a fer possible: el parc arqueològic de la Banqueta i un museu de lloc. A més de mancar mitjans econòmics, tampoc va ser una idea plenament compartida en reproduir-se el sempitern debat entre la conveniència d'instal.lar l'equipament al jaciment o al poble.

\section{A tall de cloenda}

Com a coordinador d'aquest homenatge, vull donar les gràcies a tots els/les col-legues que han contribuït a fer-lo possible amb els seus articles i la seva ràpida predisposició a acceptar el meu encàrrec. Sé que molts altres companys i companyes haurien volgut participar-hi, però no hi havia lloc per a tothom, disculpeu-me. Vull excusar també l'amic Gonzalo Ruiz Zapatero, que quan ja tenia l'article quasi llest s'ha vist sorprès per una malaltia $i$ no ha pogut lliurar-lo.

Pel que respecta a la meva aportació personal, he volgut mostrar l'Emili Junyent científic i docent, però també la seva dimensió humana. He estat deliberadament exhaustiu en l'exposició de la seva trajectòria, i encara m'he deixat moltes coses per dir, perquè també volia fer palesa la seva immensa capacitat de treball.

El dia 31 d'agost del 2016 es va jubilar per imperatius legals en absoluta plena forma física i mental i, company, no sé si la Universitat o les múltiples institucions amb les quals has col-laborat valoraran els teus esforços, però l'empremta de la teva feina ha quedat marcada i les teves aportacions científiques 
resten escrites. Els Vilars hi serà sempre i l'equip que ha estat a la teva vora reconeixerà sempre el teu mestratge i t'estarà sempre agraït. Aguanta treballant amb nosaltres mentre puguis i vulguis!

\section{Agraïments}

Aquest treball s'ha dut a terme en el marc del projecte quadriennal 2018-2021, que subvenciona l'OSIC: La fortalesa dels Vilars i l'oppidum de Gebut: Gènesi, identitat $i$ heterogeneïtat en l'ethnos ilerget (CLT009/18/00039); del projecte que subvenciona el Ministerio de Economía y Competitividad: Prácticas agroalimentarias, asentamientos y espacios domésticos.
Relaciones y evolución en los llanos sur-pirenaicos (III-I milenios ANE) (HAR2016-78277-R), i de les activitats de recerca que desenvolupa el Grup de Recerca Consolidat de la Generalitat de Catalunya (2017 SGR 1714), grup mixt UB-UdL: Estudi, Digitalització, Documentació $i$ Divulgació del Patrimoni artístic $i$ arqueològic: recerca $i$ transferència (3DPATRIMONI).

Joan B. López

Grup d'Investigació Prehistòrica Departament d'Història - Universitat de Lleida

Plaça Víctor Siurana, 1 25003 Lleida

joanlopez@historia.udl.cat

\section{Bibliografia (on no apareix Emili Junyent com a autor)}

Alonso, N. (1992). Paleoecologia i paleoeconomia a la plana occidental catalana durant la protohistòria. Aportacions de la paleobotànica. Tesi de llicenciatura inèdita. Universitat de Lleida.

Alonso, N. (ed.) (2014). Molins i mòlta al Mediterrani occidental durant l'edat del ferro. Revista d'Arqueologia de Ponent, 24: 99-362.

Alonso, N. (2015). Editorial (25 anys de la Revista d'Arqueologia de Ponent). Revista d'Arqueologia de Ponent, 25: 7-8.

Alonso, N., Buxó, R. (1989). Resultados iniciales del estudio de semillas y frutos de la Cova de Punta Farisa (Fraga, Baix Cinca). Estudios de la Antigüedad, 6/7: 49-56.

Alonso N., Buxó, R. (1995). Agricultura, alimentación y entorno vegetal en la Cova de Punta Farisa (Fraga, Huesca) durante el Bronce Medio. Espai i Temps, Quaderns del Departament de Geografia i Història de l'Estudi General de Lleida, 24. Lleida.

Armentano, N., Gallart, J., Jordana, X., López, J. B. Malgosa, A. (2008). La cova sepulcral de Montanissell (Sallent-Coll de Nargó, Alt Urgell): Pràctiques funeràries singulars durant l'edat del bronze al Prepirineu. A: 1er col-loqui d'Arqueologia d'Odèn (Solsonès): La prehistòria avui en el Prepirineu lleidatà (Odèn, 19-21 maig de 2006). Patronat del Museu Diocesà i Comarcal de Solsona: 55-72.

BALdellou, V. (1971-1972). La necrópolis prehistórica del Barranc d'En Fabra (Amposta). Boletín de la Real Sociedad Arqueológica Tarraconense, fasc. 113120: 41-49.
BARrull, J. (ed.) (2009). La Universitat de Lleida, història $i$ present. Servei de Publicacions de la Universitat de Lleida. Lleida.

Bellet, C. (2010). L’encaix urbanístic de la Universitat de Lleida a la ciutat. A: BELLET, C. (ed.). La Universitat de Lleida en la ciutat i el territori. Servei de Publicacions de la Universitat de Lleida. Lleida: 105-137.

Buxó, R., Colomer, X., López, J. B., Llorens, J. M., Martín, A., Mataró, M., Pons, E., Toledo, A. (1992). L'Illa d'en Reixac (Ullastret). Mètode d'excavació i sistema informàtic de registre. A: Trócoli, I. G., Sospreda, R. (eds.). Harris Matrix. Sistemes de registre en Arqueologia, vol II. Publicacions de l'Estudi General de Lleida i Pagès editors. Lleida: 132-183.

Currás, A. (2012). Estudio sobre la evolución de paisajes mediterráneos continentales en Lleida y Guadalajara durante los últimos 3000 años a partir de las secuencias polínicas de Ivars, Somolinos y Cañamares. Tesi doctoral. Universitat de Barcelona. Barcelona. <http:// hdl.handle.net/2445/42650>.

Gallart, J. (1982). La necròpolis d'incineració de La Pena, Torregrossa (Les Garrigues). Tesi de llicenciatura inèdita. Estudi General de Lleida.

Gallart, J. (1988). Avenç de l'estudi de la necròpolis d'incineració de La Pena (Torregrossa, el Pla d'Urgell). Quaderns d'Arqueologia del Grup de Recerques de "La Femosa", 3. Artesa de Lleida.

GIL, I. (2017). L'Arxiu Arqueològic de Lleida: un nou espai per a la difusió del patrimoni arqueològic de la ciutat. Revista d'Arqueologia de Ponent, 27: 300-310.

Gil, I., Loriente, A., Morán, M., Payà, X., Pérez, A. (2001). De la Iltirta prerromana a la Ilerda tardorromana. Nuevos 
datos tras dos décadas de investigación continuada en Lérida. Archivo Español de Arqueología, 74: 161-181.

Harbison, P. (1971). Wooden and Stone Chevaux de Frise in Central and Western Europe. Proceedings of the Prehistoric Society, XXXVII, 1971: 195-225.

Harbison, P. (1979). Celtic Migrations in Western Europe. A: Actas del II Coloquio sobre lenguas y culturas prerromanas de la Península Ibérica (Tübingen 17-19 junio 1976). Universidad de Salamanca: 225-235.

Lafuente, A., Ruiz de Arbulo, J. (1995). Arqueología urbana y registro informático en Lleida. Revista de Arqueología, 171: 6-11.

LóPEz, J. B. (1991a). Aplicacions de la microinformàtica en la recerca protohistòrica. Aproximació històrica. Revista d'Arqueologia de Ponent, 1: 151-186.

López, J. B. (1991b). La difusión del sistema de registro de Lattes en Catalunya y su adaptación en los yacimientos de "L'Illa d'en Reixac" (Ullastret, Baix Empordà) y "Els Vilars" (Arbeca, Les Garrigues). Lattara, 4: 203-207.

LóPEz, J. B. (2000). L'evolució del poblament protohistòric a la plana occidental catalana. Models d'ocupació del territori $i$ urbanisme. Tesi doctoral. Universitat de Lleida. Lleida. <http://tdx.cat/handle/10803/8220>.

López, J. B., Moya, A., Martínez, P. (2015). Els Reguers de Seró (Artesa de Segre, Catalogne): Un nouveau mégalithe avec des statues-menhirs anthropomorfes sculptées en réemploi. A: Rodriguez, G., MARchesi, H. (eds.). Statues-menhirs et pierres levées du Néolithique à aujourd'hui. Actes du 3e colloque international sur la statuaire mégalithique (Saint-Pons-de-Thomières, 1216 septembre 2012), Direction Régionale des Affaires Culturelles Languedoc-Roussillon. Saint-Pons-deThomières: 381-396.
Loriente, A. (2016). El port fluvial de "Medina Larida”. Realitat i hipòtesi de funcionament. Revista d'Arqueologia de Ponent, 26: 245-255.

Maya, J. L., Francés, J., Prada, A. (1993). El complejo arqueológico de Punta Farisa (Fraga, Huesca). Estudios de la Antigüedad, 6/7 (Barcelona).

Moreno, J. (2006). La creació de la Universitat de Lleida 1991-1992: aspectes juridicolaborals. Servei de Publicacions de la Universitat de Lleida. Lleida.

Nieto, A. (2012). Entre el consum i l'afecte. La interacció entre els animals $i$ les comunitats protohistòriques de la plana occidental catalana (segles VII - IV a.C.). Tesi doctoral. Universitat de Lleida. Lleida. <https://www. tesisenred.net/handle/10803/96488>.

Plens, M. (1986). La necròpolis de La Pedrera. Tesi de llicenciatura inèdita. Estudi General de Lleida.

Royo, J. I. (1996). Ritual funerario y cultura material en las necrópolis tumulares de Los Castellets de Mequinenza (Zaragoza): Una aportación al estudio del Bronze Final/Hierro en el N.E. Peninsular. Gala, 3-5: 93-108.

Ruiz Zapatero, G. (1985). Los Campos de Urnas del NE de la Península Ibérica. Tesi doctoral (1983), 2 vols. Universidad Complutense de Madrid. Madrid.

Ruiz Zapatero, G. (1998). Fragmentos del pasado: la presentación de sitios arqueológicos y la función social de la arqueología. A: González Marcén P. (ed.). Actes del II seminari Arqueologia i Ensenyament (Universitat Autònoma de Barcelona, 12-14 novembre 1998). Treballs d'Arqueologia, 5: 7-34.

VILA, S. (2018). L'explotació dels recursos vegetals a la plana occidental catalana durant la protohistòria a partir de l'anàlisi antracològica (III-I mil.lenni). Tesi doctoral inèdita. Universitat de Lleida. 


\section{Articles en revistes}

Pla, J., Junyent, E. (1970). Noticia sobre el hallazgo de un vaso en la Cova dels Lladres (Vacarisses, Barcelona). Pyrenae, 6: 43-46.

Maluquer de Motes, J., Llorens, A., Baldellou, V., Junyent, E., Cura, M. (1971). Colaboración de la Universidad de Barcelona en las excavaciones del poblado ibérico del Molí d’Espígol, en Tornabous. Pyrenae, 7: 19-46.

JunYent, E. (1972a). Los materiales del poblado ibérico de Margalef, en Torregrossa (Lérida). Pyrenae, 8: 89-132.

Junyent, E. (1972b). Sobre una vasija ibérica del poblado de Margalef en Torregrossa (Lérida). Boletín Arqueológico Real Sociedad Arqueológica Tarraconense, 1971-1972, época IV, fasc. 113-120: 69-72.

Junyent, E., Baldellou, V. (1972a). Estudio de una casa Ibérica en el poblado de "Mas Boscá", Badalona (provincia de Barcelona). Príncipe de Viana, Año 33, 126-127: 5-68.

Junyent, E. (1973a). El primer corte estratigráfico realizado en Roques de Sant Formatge (Serós, Lérida) y algunas cuestiones en torno a la formación de la cultura ilergeta. Noticiario Arqueológico Hispánico, Prehistoria II. Madrid: 289-386.

Junyent, E. (1974a). Acerca de la cerámica de barniz rojo aparecida en el área ilergeta. Pyrenae, 10: 109-133.

Junyent, E. (1974b). Cerámica barnizada de negro del poblado ibérico de Margalef, en Torregrossa, Lérida. Miscelánea Arqueológica. Tomo I. Diputación Provincial de Barcelona. Barcelona: 379-396.

JunYENT, E. (1976a). Observaciones a unas cerámicas pintadas de Almenara (Castellón de la Plana). Cuadernos de Prehistoria y Arqueología Castellonenses, 3: 195-204.

JunYent, E. (1976b). La filiación cultural del horizonte ibérico antiguo en tierras catalanas. Tesi doctoral inèdita. Universitat de Barcelona. Barcelona.

Junyent, E. (1979a). Aproximació a l'obra de Lluís Pericot. L'Avenç, 13: 5-6.

Junyent, E. (1979b). Els ilergetes. L'Avenç, 14: 35-42.

JunYENT, E. (1981a). Introducció al dossier: Emporion, la ciutat grega d'Empúries. L'Avenç, 38: 20.

Junyent, E. (1981b). Emporion i la iberització de Catalunya. L'Avenç, 38: 36-41.

Junyent, E., Prieto, A. (1981). Conversa amb Andrea Carandini. L'Avenç, 37: 64-68.

Junyent, E. (1982). L'origen de la cultura ibèrica. L'Avenç, 54: 63-65.
Junyent, E., Pérez, A. (1982). El yacimiento romano de La Fonteta de Grealó (Lleida, Segrià). Ilerda, XLIII: 63-93.

Junyent, E., Pérez, A. (1983). Noves dades sobre la ciutat romana d'Ilerda. Tribuna d'Arqueologia 19821983. Departament de Cultura de la Generalitat de Catalunya. Barcelona: 63-73.

Junyent, E., Olaria, C., Gusi, F., Aguiló, P., Roman, I., SESER, R. (1983). El Abric de Les Cinc (Almenara, Castellón). $2^{\text {a }}$ campaña de excavaciones 1977. Cuadernos de Prehistoria y Arqueología Castellonenses, 9 (19821983): 55-122.

Junyent, E., Pérez, A., Rafel, N. (1985). Lleida: notes a l'arqueologia de la ciutat. Cota Zero: revista d'arqueologia i ciència, 1: 23-28.

\section{MARC-7:}

Dupré, X., Granados, O., Junyent, E., Nieto, J., Rafel, N., TARrats, F. (1986a). El procés de consolidació de l'arqueologia catalana. L’Arqueologia catalana-I. L'Avenç, 90: 55-61.

\section{MARC-7:}

Dupré, X., Granados, O., Junyent, E., Nieto, J., Rafel, N., TARrats, F. (1986b). De la postguerra als anys setanta. L'Arqueologia catalana-II. L'Avenç, 91: 64-71.

\section{MARC-7:}

Dupré, X., Granados, O., Junyent, E., Nieto, J., Rafel, N., TARRats, F. (1986c). Reorganització i nous impulsos. 1975-1985. L'Arqueologia catalana-III. L'Avenç, 92: 47-53.

Junyent, E., Prieto, A. (1987). Monique Clavel-Levêque i Jacques Annequin: les formacions socials a l'Antiguitat. L'Avenç, 104: 44-49.

Junyent, E., Pérez, A., Rafel, N. (1988). Desenvolupament i futur de l'arqueologia a la ciutat de Lleida, 1980-1988. L'Avenç, 117: 241-248.

Junyent, E. (1989). Arqueologia catalana: entre el mite i la realitat. L'Avenç, 124: 17-21.

Garcés, I., Junyent, E. (1989a). El poblat dels Camps d'Urnes i ibèric de Vilars (Arbeca, Les Garrigues). Tribuna d'Arqueologia 1987-1988. Departament de Cultura de la Generalitat de Catalunya. Barcelona: 103-114.

Garcés, I., JunYent, E. (1989b). Fortificación y defensa en la I Edad del Hierro. Piedras hincadas en Els Vilars. Revista de Arqueología, 93: 38-49.

Junyent, E. (1991). Joan Maluquer de Motes i Nicolau (1915-1988). Revista d'Arqueologia de Ponent, 1: 5.

Junyent, E., Alastuey, A. (1991). La vaixella ilergeta de vernís roig. Revista d'Arqueologia de Ponent, 1: 9-50. 
Junyent, E. (1992). Els orígens del ferro a Catalunya. Revista d'Arqueologia de Ponent, 2: 21-35.

Junyent, E. (1993). L'arqueologia com a àrea de coneixement universitària. Arqueologia i reforma dels plans d'estudis. Revista d'Arqueologia de Ponent, 3: 335-338.

Junyent, E., Lafuente, A., López, J. B. (1994). L’origen de l'arquitectura i de l'urbanisme a la Catalunya occidental. Cota Zero: revista d'arqueologia i ciència, 10: 73-89.

Junyent, E., PÉrez, A. (1994). Los restos arqueológicos de la plaza de Sant Joan de Lleida, I. Revista d'Arqueologia de Ponent, 4: 173-203.

Junyent, E., López, J. B., Martín, A. (1995). Datació radiocarbònica i calibratge. Revista d'Arqueologia de Ponent, 5: 249-251.

Junyent, E., PÉrez, A. (1995). Los restos arqueológicos de la plaza de Sant Joan de Lleida, II. Revista d'Arqueologia de Ponent, 5: 211-246.

Garcés, I., Junyent, E., Lafuente, A., López, J. B. (1996). Els Vilars (Arbeca, les Garrigues). Primera edat del ferro i època ibèrica a la plana occidental catalana. Actividad Científica, 9: 16-17.

\section{Equip Minferri:}

Agustí, B., Alonso, N., Borràs, H., Bruguera, R., Ferrer, C., Gomis, M., Gonzalo, C., Junyent, E., Lafuente, A., López, J. B., Noguera, J., Llussà, A., Mazo, C., Mirada, J., Miró, J. M., Morán, M., Rey, J., Rovira, C., Rovira, N., Saula, O., Tartera, E. (1997). Noves dades per a la caracterització dels assentaments a l'aire lliure durant la primera meitat del II mil.lenni cal. BC: primers resultats de les excavacions en el jaciment de Minferri (Juneda, les Garrigues). Revista d'Arqueologia de Ponent, 7: 161-211.

Junyent, E. (1999). Patrimoni arqueològic, difusió i mercat: algunes reflexions. Cota Zero: revista d'arqueologia i ciència, 15: 9-27.

Junyent, E. (2000). Arqueologia contractual: qui es menja el pastís? Revista d'Arqueologia de Ponent, 10: 365.

Alonso, N., Junyent, E., Lafuente, A., López, J. B., Tartera, E. (2000a). La fortaleza de Arbeca. El Proyecto Vilars 2000. Investigación, recuperación y socialización del conocimiento y del patrimonio. Trabajos de Prehistoria, 57 (2): 161-173.

\section{Equip Sarró:}

Alonso, N., Clemente, J. I., Ferrer, C., Gené, M., Gibaja, J. F., Juan-Muns, N., Junyent, E., Lafuente, A., López, J. B., Llussà, A., Mirada, J., Miró, J. M., Morán, M., Roca, J., Ros, M. a T., Rovira, C., Tartera, E. (2000). Les Roques del Sarró (Lleida, Segrià): Evolució de l'assentament entre el 3600 cal. a.n.e. i el 175 a.n.e. Revista d'Arqueologia de Ponent, 10: 103-173.

Junyent, E. (2002). La fortalesa d'Arbeca i Emporion. Dos escenaris de memòria virtual per a entendre la iberització. Àrnica, 53, època III: 20-29.
Maya, J. L., López, F. J., GonzÁlez, J. R., Junyent, E., RodríGuEz, J. I. (2002). Excavaciones (1981-1983) en el poblado de Carretelà (Aitona, Segrià, Lleida). Revista d'Arqueologia de Ponent, 11-12 (2001-2002): 151-233.

Lorés, J., Junyent, E. (2003). Proyecto Vilars-RA. Realidad aumentada para visitar la Fortaleza de Els Vilars. PH. Boletín del Instituto Andaluz del Patrimonio Histórico: Especial Monográfico: Patrimonio y TIC, 46: 92-93.

JunYent, E. (2005). Workshop "De la aldea a la ciuitas: materialitat i ideologia. Contrastació de models al nordoest del Mediterrani durant el II i I mil.lenni ane" (Lleida, 3 de desembre de 2004). Revista d'Arqueologia de Ponent, 15: 9-12.

Moya, A., López, J. B., Lafuente, A., Rey, J., Tartera, E., Vidal, A. i Equip Vincamet: Agustí, B., Alonso, N., Bergadì, M., Gallart, J., Junyent, E., Llussà, A., Nieto, A., Mazo, C., Piqué, R., Ramos, N., Sánchez, A. (2005). El Grup del Segre-Cinca II (1250-950 cal. a.n.e.) a les terres del Baix Cinca: el poblat clos de Vincamet (Fraga, Osca). Revista d'Arqueologia de Ponent, 15: 13-58.

Colet, A., Gené, M. i GIP: Alonso, N., Junyent, E., Escala, O., Moya, A., Lafuente, A., López, J. B. (2005). El món funerari durant el Grup del Segre-Cinca III (950-750 cal a.n.e.): la necròpolis de Roques de Sant Formatge (Seròs, el Segrià). Revista d'Arqueologia de Ponent, 15: 151-163.

Alonso, N., Junyent, E., Lafuente, A., López, J. B. (2008). Plant remains, storage and crop processing inside the Iron Age fortress of Els Vilars d'Arbeca (Catalonia, Spain). Vegetation History and Archaeobotany, 17 (Suppl 1): 149-158.

Junyent, E. (2009). El Pla Integral d'Arqueologia de Catalunya (PIACAT): ¿per construir junts el futur de l'arqueologia? Revista d'Arqueologia de Ponent, 19: 375-378.

Junyent, E., López, J. B. (2009). Dossier: Portes i sistemes d'accés en les fortificacions protohistòriques del Mediterrani occidental. Presentació. Revista d'Arqueologia de Ponent, 19: 175-176.

Junyent, E., López, J. B., Moya, A., Tarter, E. (2009). Laccés fortificat i les portes en el sistema defensiu de la fortalesa dels Vilars (Arbeca, les Garrigues). Revista d'Arqueologia de Ponent, 19: 307-333.

JuNYENT, E. (2010). El futur: simbiosi recerca-patrimoni, socialització i polítiques públiques. Cota Zero: revista d'arqueologia $i$ ciència, 25: 62-67.

Junyent, E., López, J. B., Mastria, F. (eds.) (2011a). Dossier: Les defenses exteriors i la poliorcètica mediterrània preromana: els fossats, segles VIII a III a.n.e. Revista d'Arqueologia de Ponent, 21: 91-295.

Junyent, E., López, J. B., Mastria, F. (2011b). Introducció. A: Junyent, E., López, J. B., Mastria, F. (eds.). Dossier: 
Les defenses exteriors i la poliorcètica mediterrània preromana: els fossats, segles VIII a III a.n.e. Revista d'Arqueologia de Ponent, 21: 91-92.

Junyent, E., Moya, A. (2011). Els fossats de la Fortalesa dels Vilars d'Arbeca (Catalunya, Espanya). A: JunYent, E., López, J. B., Mastria, F. (eds.). Dossier: Les defenses exteriors i la poliorcètica mediterrània preromana: els fossats, segles VIII a III a.n.e. Revista d'Arqueologia de Ponent, 21: 93-120.

Junyent, E., Poch, R. Mª Balasch, C., Sala, R. (2011). La Fortalesa de l'aigua. Els fossats i el pou dels Vilars d'Arbeca: primeres lectures. Tribuna d'Arqueologia 2009-2010. Departament de Cultura de la Generalitat de Catalunya. Barcelona: 153-184.

Rafel, N., Junyent, E. (eds.) (2013). Dossier: Joan Maluquer de Motes Nicolau en el vint-i-cinquè aniversari de la seva mort. Revista d'Arqueologia de Ponent, 23: 273-476.

Junyent, E. (2013). A la memòria del mestre. A: RAFEL, N., Junyent, E. (eds.). Dossier: Joan Maluquer de Motes Nicolau en el vint-i-cinquè aniversari de la seva mort. Revista d'Arqueologia de Ponent, 23: 273-279.

Poch, R. M. a , Junyent, E., Balasch, C. (2014). Funcionament del pou-cisterna de la fortalesa ibera dels Vilars, Arbeca, les Garrigues: evidències de mesures en camp de conductivitat elèctrica de l'aigua en períodes de reg del canal d'Urgell. Quaderns Agraris, 36: 51-64.

Junyent, E., Poch, R. Ma , Balasch, C. (2014). Water and defense systems in Els Vilars fortress (Arbeca, Catalonia, Spain): a multiproxy approach. Cypsela, 19 (2012): 49-70.

Junyent, E., López, J. B. (2015). Les excavacions dels anys 1973-1974 i 1980 al Tossal del Molinet (el Poal, Pla d'Urgell): una aldea de la primera edat del ferro i època ibèrica. Mascançà. Revista d'Estudis del Pla d'Urgell, 6: 73-98.

Nieto, A., López, J. B., Gardeisen, A., Junyent, E. (2018). Votive well or refuse tip? Chronicle of an abandonment: taphonomic study of the faunal remains of an iron age well-cistern. Historical Biology, 30: 894-915.

Rafel, N., Junyent, E., Alonso, N. (2017). La investigació arqueològica en el sistema públic de ciència: grups de recerca, universitats i instituts. Revista d'Arqueologia de Ponent, 27: 269-271.

\section{Ressenyes en revistes}

Junyent, E. (1972). Recensió a: Picard, G. Ch., Picard, C.: Vie et mort de Carthage. Hachette, Paris, 1970. Pyrenae, 8: 195-196.

Junyent, E. (1973b). Recensió a: Lagrand, Ch., Thalmann, J. P.: Les habitats protohistoriques du Pègue (Drôme).
Le sondage $n^{\circ} 8$ (1957-1971), Centre de Documentation de la Prehistoire Alpine, Cahier, no 2, Grenoble, 1973, 159 p., 23 figs., XXXIX làms. Pyrenae, 9: 200-202.

Junyent, E. (1973c). Recensió a: Llobregat, E. A.: Contestania Ibèrica, Instituto de Estudios Alicantinos, Alicante, 1972. Pyrenae, 9: 202-205.

Junyent, E. (1987). Ressenya a: Cota Zero: Revista d'Arqueologia i Ciència, 2, 1986. L'Avenç, 101: 71.

Junyent, E. (2008). Ressenya a: Moret, P., Benavente Serrano, J. A., Gorgues, A.: Iberos del Matarraña. Investigaciones arqueológicas en Valdetormo, Calaceite, Cretas y La Fresneda (Teruel). Al-Qannis II, Número Monográfico, Taller de Arqueología de Alcañiz y Casa de Velázquez, Alcañiz (Teruel), 2006. Trabajos de Prehistoria, 65 (1): 194-196.

Junyent, E. (2009a). Ressenya a: J. Antón: Pilotos, caimanes y otras aventuras extraordinarias, RBA Libros S.A., Barcelona, 2009: 351. Revista d'Arqueologia de Ponent, 19: 398-400.

Junyent, E. (2009b). Ressenya a: Quesada F.: Ultima ratio regis. Control y prohibición de las armas desde la Antigüedad a la Edad Moderna, Editorial Polifemo, Madrid, 2009: 487. Revista d'Arqueologia de Ponent, 19: 401-404.

Junyent, E. (2010). Resenya a: Quesada SAnz, F.: Armas de la antigua Iberia. De Tartesos a Numancia, con ilustraciones de Carlos Fernández del Castillo. La Esfera de los Libros, Madrid, 2010, 298. Revista d'Arqueologia de Ponent, 20: 305-309.

Junyent, E. (2011). Ressenya a: La musealización de yacimientos ibéricos. XII Curso de Arte y Arqueología ibérica (Segura de la Sierra, Jaén, 6, 7 y 8 de mayo de 2010). Centro Andaluz de Arqueología Ibérica. Universidad de Jaén. Revista d'Arqueologia de Ponent, 21: 299-302.

Junyent, E. (2012). Ressenya a: Bonet, H., VivesFERrÁndiz, J. (eds.): La Bastida de les Alcusses 19282010, Museu de Prehistòria, Diputació de València, València: 328. Revista d'Arqueologia de Ponent, 22: 240-243.

Junyent, E. (2013). Ressenya a: Gracia, F.: Pere Bosch Gimpera. Universidad, política, exilio, Marcial Pons, Historia, Madrid, 2011: 607. Revista d'Arqueologia de Ponent, 23: 514-519.

Junyent, E. (2014). Ressenya a: Rovira Hortalà, M. C., López CAchero, F. J., Mazière, F. (dirs.): Les necròpolis d'incineració entre l'Ebre i el Tíber (segles IX-VI $\mathrm{aC)}$ : metodologia, pràctiques funeràries i societat. Monografies Museu d'Arqueologia de Catalunya, 14. Generalitat de Catalunya. Barcelona, 2012, 451. Trabajos de Prehistoria, 71 (1): 177-179.

Junyent, E. (2015a). Ressenya a: Gual, J., Simón Gornés, J. (2015). Menorca talayótica. Guía de yacimientos. Consell Insular de Menorca i RgM 
edicions. Menorca. 165. Sintes, E. (2015). Guia. Menorca talaiòtica. La prehistòria de l'illa. Triangle Postals SL, Sant Lluís. Menorca. Revista d'Arqueologia de Ponent, 25: 386-390.

Junyent, E. (2016). Ayán Vila, X. (2015). Altamira vista por los españoles. JAS Arqueología Editorial, Madrid. 301. Revista d'Arqueologia de Ponent, 26: 355-363.

Junyent, E. (2017). Ressenya a: MALuquer, Jordi (2017). L'arqueòleg Maluquer de Motes i el creuer universitari per la Mediterrània de 1933. Eumo Editorial. Vic. Revista d'Arqueologia de Ponent, 27: 329-336.

\section{Publicacions en obres col-lectives}

Junyent, E. (1973d). Noticia acerca del primer corte estratigráfico efectuado en el poblado de Roques de Sant Formatge (Serós, Lérida). Crónica del XII Congreso Arqueológico Nacional (Jaén 1971). Universidad de Zaragoza. Zaragoza: 495-502.

Junyent, E. (1974). El Antiguo Oriente. Enciclopedia Temática Planeta. Historia Antigua y Medieval. Ed. Planeta. Barcelona.

Junyent, E., Martí, F. (1974). La Antigüedad griega. Enciclopedia Temática Planeta. Historia Antigua y Medieval. Ed. Planeta. Barcelona.

JunYent, E. (1975). Contexto y significado histórico de la cerámica de barniz rojo ilergeta en la iberización del Norte del Ebro. A: Crónica del XIII Congreso Arqueológico Nacional (Huelva 1973). Universidad de Zaragoza. Zaragoza: 715-722.

JunYent, E. (1976). Intervencions. A: Le Languedoc au I Age du Fer. Journées d'Études de Sète 8 juin 1975. Federation Archéologique de l'Hérault. Sète: 60-68.

Junyent, E. (1978a). La formació del substrat bàsic. Història de Catalunya Salvat, vol. I. Salvat Editores S.A. Barcelona: 119-139.

Junyent, E. (1978b). Problemática general de la iberización en la Cataluña Interior. A: RipolL, E., Llongueras, M., Sanmartí, E. (eds.). Simposi Internacional: Els Orígens del món ibèric (BarcelonaGirona, 2-7 maig 1977). Ampurias, 38-40 (1976-1978): 177-185.

Junyent, E. (1982a). Tossal del Molinet, El Poal. Les excavacions arqueològiques a Catalunya en els darrers anys. Excavacions Arqueològiques a Catalunya, 1. Departament de Cultura de la Generalitat de Catalunya. Barcelona: 256-257.

Junyent, E. (1982b). La Pedrera, Vallfogona de BalaguerTérmens. Les excavacions arqueològiques a Catalunya en els darrers anys. Excavacions Arqueològiques a Catalunya, 1. Departament de Cultura de la Generalitat de Catalunya. Barcelona: 262.
Junyent, E. (1982c). Els Vilars, Serós-Aitona. Les excavacions arqueològiques a Catalunya en els darrers anys. Excavacions Arqueològiques a Catalunya, 1. Departament de Cultura de la Generalitat de Catalunya. Barcelona: 266-267.

Junyent, E. (1982d). La Pena, Torregrossa. Les excavacions arqueològiques a Catalunya en els darrers anys. Excavacions Arqueològiques a Catalunya, 1. Departament de Cultura de la Generalitat de Catalunya. Barcelona: 268-269.

Junyent, E. (1982e). Plaça de Sant Joan, Lleida. Les excavacions arqueològiques a Catalunya en els darrers anys. Excavacions Arqueològiques a Catalunya, 1. Departament de Cultura de la Generalitat de Catalunya. Barcelona: 367-368.

Junyent, E. (1983). La Plaça de Sant Joan (Lleida). Coneixes la teva ciutat? Ateneu Popular de Ponent. Lleida: 1-7.

Junyent, E., Barbera, J. (1983). Cultura Ibérica. A: Arqueología en Catalunya. Datos para una sintesis. Departament de Cultura de la Generalitat de Catalunya. Barcelona: 93-95.

Junyent, E., González, J. R., Maya, J. L., Rodríguez, J. I. (1983). Carretelà (Aitona, Segrià). Arqueología 82. Ministerio de Educación y Cultura. Madrid: 183.

Junyent, E., Pérez, A. (1983). La Paeria (Lleida, Segrià). Arqueología 82. Ministerio de Educación y Cultura. Madrid: 174.

Junyent, E., Sanmartí, E. (1983). Primeras relaciones con el Mediterráneo oriental. A: Arqueología en Catalunya. Datos para una síntesis. Departament de Cultura de la Generalitat de Catalunya, Barcelona: 87.

Junyent, E., Pérez, A. (1985). Las cerámicas paleocristianas de la Paeria, Lleida. A: XVII Congreso Nacional de Arqueología (Logroño 1983). Secretaría General de los Congresos Arqueológicos Nacionales. Zaragoza: 903-918.

Junyent, E. (1986). El poblament ibèric a l'àrea ilergeta. A: PADró, J. (ed.). 6è Col.loqui Internacional de Puigcerdà: Protohistòria catalana (Puigcerdà 7-9 desembre 1984). Institut d'Estudis Ceretans. Puigcerdà: 257-263.

Gallart, J., Junyent, E. (1986). El jaciment del Bronze Final de Rocaferida (Sarroca de Lleida, Segrià). A: PAdró, J. (ed.). Gè Col.loqui Internacional de Puigcerdà: Protohistòria catalana (Puigcerdà 7-9 desembre 1984). Institut d'Estudis Ceretans. Puigcerdà: 115-126.

Junyent, E. (1987). El poblamiento ibérico en el área ilergeta. A: Ruiz, A., Molinos, M. (eds.). Iberos. Actas de las I Jornadas sobre Mundo Ibérico (Jaén junio 1985). Ayuntamiento de Jaén - Junta de Andalucía. Jaén: 57-65.

Alcalde, G., Junyent, E., Pérez, A., Pons, E., Soler, N., TARRÚs, J. (1988). Ingrés als museus de materials 
arqueològics. A: Museus documentació. Arqueologia. Generalitat de Catalunya. Departament de Cultura. Barcelona: 1-12.

JunYENT, E. (1989). La evolución del hábitat en la Catalunya occidental durante la Edad del Bronce, primera Edad del Hierro y época ibérica. A: Pré-actes colloque international: Habitats et structures domestiques en Méditerranée occidentale durant la Protohistore (Arles-sur-Rhône, 19-21 octobre 1989). Imprimerie Louis-Jean. Gap: 95-105.

JunYent, E., Garcés, I. (1989). El poblado fortificado de los Campos de Urnas Tardíos en Els Vilars, Arbeca, Lleida. Crónica del XIX Congreso Nacional de Arqueología (Castelló, 1987), vol. II. Universidad de Zaragoza. Zaragoza: 329-339.

Junyent, E., Pérez, A., Rafel, N. (1989a). Arqueologia i ciutat. A: III Setmana d'Estudis Urbans a Lleida: Història urbana i intervenció al Centre Històric (Lleida, 6-10 octubre 1986). Institut Cartogràfic de Catalunya. Barcelona: 95-105.

Junyent, E., Pérez, A., Rafel, N. (1989b). Archaeology in the city of Lleida (Catalonia, Spain) during the eighties, Archaeology and Society. Large scale rescue operations-their possibilities and problems. A: Papers presented at the Archaeology and Society Symposium in Stockholm 12-16 September 1988 / ICOMOS International Committee on Archaeological Heritage Management. ICAHM Nordic Secretariat. Stockholm: 227-231.

Junyent, E. (1991a). Contribució al coneixement de les estructures defensives en els assentaments de la Catalunya Occidental. Bronze Final, Primera Edat del Ferro i Ėpoca Ibèrica. Estat de la qüestió. A: Simposi Internacional d'Arqueologia Ibèrica: Fortificacions, la problemàtica de l'Ibèric Ple (segles IV-III a.C.) (Manresa, 6-9 de desembre de 1990). Centre d'Estudis del Bages. Manresa: 103-108.

Junyent, E. (1991b). Pròleg. A: Gallart, J., El dipòsit de bronzes de Llavorsí, Pallars Sobirà. Excavacions Arqueològiques a Catalunya, 10. Departament de Cultura de la Generalitat de Catalunya. Barcelona: 9-10.

Junyent, E. (1991c). Prólogo. A: Harrris, E. C. Principios de estratigrafía arqueológica. Ed. Crítica. Barcelona: 7-15.

Garcés, I., Junyent, E., Lafuente, A., López, J. B. (1991a). El sistema defensiu de Els Vilars (Arbeca, les Garrigues). A: Actes del Simposi Internacional d'Arqueologia Ibèrica: Fortificacions. La problemàtica de l'Ibèric Ple (segles IV-III aC) (Manresa, 6-9 de desembre de 1990). Centre d'Estudis del Bages. Societat Catalana d'Arqueologia. Manresa: 183-197.

Garcés, I., Junyent, E., Lafuente, A., López, J. B. (1991b). Sistema de registro i tratamiento automático de la información en el yacimiento protohistórico de Els Vilars (Arbeca, Lleida). A: Fernández, V. M., FERnÁdez, G. (coords.). Actas de la Reunión: Aplicaciones informáticas en Arqueología (Universidad Complutense de Madrid, 8-9 octubre 1990). Complutum, 1: 189-210.

\section{MARC-7:}

Dupré, X., Junyent, E., Rafel, N., Ruiz de Arbulo, J., Tarrats, F. (1991). Presentació i Conclusions. A: Jornades sobre protecció legal del patrimoni arqueològic (Barcelona, 3 i 4 de maig de 1991). Dossier d'informació i documentació pels Municipis, 6. Diputació de Barcelona. Barcelona: 153.

Junyent, E. (1992). Veus: Amusic, Arqueologia, Arqueologia experimental, Arqueologia industrial, Arqueologia Subaquàtica, Arqueologia urbana, Bilistages, Colomina, La (Gerb), Empúries (L’Escala), Estratigrafia, Excavació, Genó (Aitona), Gebut (Soses), Iberia, Ibèric cultura, Ilerget, Indíbil (Indíbil i Mandoni), Jaciment, Maluquer de Motes Joan, Moleta del Remei (Alcanar), Pedrera, La (Vallfogona de Balaguer- Termens), Pericot Lluís. Diccionari d'Història de Catalunya. Edicions 62. Barcelona.

Junyent, E., López, J. B., Oliver, A. (1992). Estratègia, anàlisi estratigràfica i registre en l'Arqueologia lleidatana dels 80. La Harris Matrix. A: Trócoli, I. G., SospredA, R. (eds.). Harris Matrix. Sistemes de registre en Arqueologia, vol II. Publicacions de l'Estudi General de Lleida. Pagès editors. Lleida: 184-275.

Junyent, E. (1994). Iltirda. A: Leyenda y arqueología de las ciudades prerromanas de la Península Ibérica: ciclo de conferencias, Madrid, 25 y 26 de noviembre de 1993. Museo Arqueológico Nacional. Madrid: 77-94.

Junyent, E., Pérez, A. (1994). El Bajo Imperio ilerdense: las excavaciones de la Paeria. A: III Reunió d'Arqueologia Cristiana Hispànica (Maó, 12-17 setembre 1988). Institut d'Estudis Catalans. Barcelona: 127-150.

Garcés, I., Junyent, E., Lafuente, A., López, J. B. (1994). Els Vilars (Arbeca, les Garrigues). Primera edat del ferro i època ibèrica a la plana occidental catalana. A: Actes del Seminari: El poblament ibèric a Catalunya (Museu Comarcal del Maresme-Mataró, 25-26 març 1993). Laietània. Estudis d'Història i d'Arqueologia del Maresme, 8 (1993): 43-59.

Junyent, E. (1995). Capítols: 9. Edat del bronze, 10. Ritus funeraris dels camps d'urnes, 12. Ibers. L'evolució del poblament laietà, 13. Assentaments ibèrics. Poblats i necròpolis, 14. Ilergets. Civilització i hàbitat ibèric, 15. Segona Guerra Púnica, conquesta i guerra civil. A: Hurtado, V., Mestre, J., Miserachs, T. (dirs.). Atles d'Història de Catalunya. Edicions 62. Barcelona: 336.

Junyent, E. (1996a). Els orígens de la cultura ilergeta. A: GARcÉs, I. (coord.). Indíbil i Mandoni, reis i guerrers. Catàleg de l'exposició. Ajuntament de Lleida. Lleida: 13-16.

Junyent, E. (1996b). La societat ilergeta: un món de pagesos i aristòcrates. A: GARcÉs, I. (coord.). Indíbil i Mandoni, reis $i$ guerrers. Catàleg de l'exposició. Ajuntament de Lleida. Lleida: 17-25. 
JunYEnt, E. (1996c). Introducció. Recerca i lectura del passat. A: JunYENT, E. (dir.). Els temps prehistòrics $i$ antics fins al segle V. Història, Política, Societat i Cultura dels Països Catalans. Vol I. Enciclopèdia Catalana S.A. Barcelona: 28-83.

JunYent, E. (1996d). ¿Una cultura campaniforme? A: JuNYENT, E. (dir.). Els temps prehistòrics $i$ antics fins al segle V. Història, Política, Societat $i$ Cultura dels Països Catalans. Vol I. Enciclopèdia Catalana S.A. Barcelona: 188-189.

JunYENT, E. (1996e). El poblat fortificat dels Vilars (Arbeca). A: JunYENT, E. (dir.). Els temps prehistòrics $i$ antics fins al segle $v$. Història, Política, Societat i Cultura dels Països Catalans. Vol I. Enciclopèdia Catalana S.A. Barcelona: 254-255.

Alonso, N., Garcés, I., Junyent, E., Lafuente, A., López, J. B., Miró, J. Ma , Ros, M${ }^{\mathrm{a}}$ T., Rovira, M ${ }^{\mathrm{a}}$ C. (1996). L'assentament de Els Vilars (Arbeca, les Garrigues): Territori, recursos i activitats productives. A: RovirA, J. (coord.). Actes de la Taula Rodona: Models d'ocupació, transformació $i$ explotació del territori entre el 1600 i el 500 ANE a la Catalunya meridional i zones limitrofes de la Depressió de l'Ebre (Sant Feliu de Codines, 1819 novembre 1994). Gala, 3-5 (1994-1996): 319-339.

Junyent, E. (1997). Pere Bosch i Gimpera. A: Les Ibères. AFAA - Ministerio de Educación y Cultura Fundación "la Caixa"- Kunst- und Ausstellungshalle der Bundesrepublik Deutschland. Barcelona: 72-75.

Junyent, E. (1998). Pere Bosch i Gimpera. A: Los Iberos, príncipes de Occidente. Fundació "la Caixa". Barcelona: 72-75.

Alonso, N., Junyent, E., Lafuente, A., López, J. B. (1998). Poder, símbolo y territorio: el caso de la fortaleza de Arbeca. A: ArAnegui, C. (coord.). Actas del Congreso Internacional: Los Iberos, Príncipes de Occidente. Estructuras de poder en la sociedad ibérica (Barcelona, 12-14 de març de 1998). Fundació "la Caixa". Barcelona: 355-372.

Alonso, N., Junyent, E., Lafuente, A., López, J. B. (1999). Chronométrie de l'Âge des Métaux dans la basse vallée du Segre (Catalogne, Espagne) à partir des datations ${ }^{14}$ C. A: Evin J., Oberlin C., Daugas, J. P., Salles, J. F. (dirs.). Actes du 3ème Congrès International: ${ }^{14} \mathrm{C}$ et Archéologie (Lyon, 6-10 avril 1998). Mémoires de la Société Préhistorique Française, XXVI et Supplément 1999 de la Revue d'Archéométrie: 287-292.

Agustí, B., Alonso, N., Garcés, I., Junyent, E., Lafuente, A., López, J. B. (2000). Una inhumación múltiple de perinatales en la fortaleza de Els Vilars (Arbeca, Lleida) y las prácticas de enterramiento en hábitat durante la $\mathrm{I}^{\mathrm{a}}$ Edad del Hierro en el valle del Segre (Cataluña). A: Dedet, B., Gruat, P., Marchand, G., Py, M., Schwaller, M. (eds.). Actes du XXIe Colloque International de l'AFEAF: Archéologie de la mort, Archéologie de la tombe au Premier Âge du Fer. (Conques-Montrozier, 8-11 mai 1997). Monographies d'Archéologie Méditerranéenne, 5, ARALO. Lattes: 305-324.
Alonso, N., Muñoz, D., Junyent, E., Lafuente, A., López, J. B., Lorés, J., Pérez, M., Tartera, E. (2000b). Virtual reality as an extension of the archaeological record. Reconstruction of an Iron Age fortress: Els Vilars (Arbeca, Catalonia, Spain). A: Barceló, J. M., Forte, M., SANDERs, D. H. (eds.). Virtual Reality in Archaeology. BAR International Series 843. Oxford: 225-231.

Garcés, I., Junyent, E., Lafuente, A., López, J. B. (2000). L'habitat dans la moyenne et basse vallée du Segre au Ier Âge du Fer. Le cas du village fortifié de Els Vilars (Arbeca, Lleida). A: Gasco, J., TreinenClaustre, F. (dirs.). XXIV Congrès Préhistorique de France: Habitats, economies et Sociétés du Nord-Ouest Méditerranéen de l'Age du Bronze au Premier Age du Fer (Carcasonne 23-30 septembre 1994). Société Préhistorique Française. Paris: 147-157.

Junyent, E. (2001). Presentació: Colors de Terra. La vida i la mort en una aldea d'ara fa 4.000 anys. Minferri (Juneda). Quaderns de la Sala d'Arqueologia, 1, Institut d'Estudis Ilerdencs. Lleida: 9-11.

Aguiló, C., Lorés, J., Junyent, E. (2001). Enhanced Cultural Heritage Environments by Augmented Reality Systems. A: Proceedings of the Seventh International Conference on Virtual Systems and Multimedia (VSMM'01) (Berkley, 25-27 october 2001). IEEE Computer Society. Washington DC: 357-364.

Alonso, N., Balaguer, A., Bon, S., Ferré, G., Junyent, E., Lafuente, A., López, J. B., Lorés, J., Muñoz, D., Sendin, M., Tartera, E. (2001). Análisis de escenarios de futuro en realidad aumentada. Aplicación al yacimiento de Els Vilars. A: Abascal, J., García, F. J., GIL, A. B. (eds.). Interacción 2001. $2^{\circ}$ Congreso Nacional de Interacción Persona-Ordenador (Salamanca, 16-18 mayo 2001). Ediciones Universidad de Salamanca. Salamanca: 357-367.

Balaguer, A., Lorés, J., Junyent, E., Ferré, G. (2001). Scenario based design of augmented reality systems applied to cultural heritage. A: Proceedings of the 1st Panhellenic Conference with International Participation on Human-Computer Interaction PC HCI 2001 (December 7-9, Patras, Greece). Typorama Publications. Patras.

JunYent, E. (2002a). Els segles de formació: el bronze final a la primera edat del ferro a la depressió de l'Ebre. A: Actes I Jornades d'Arqueologia de Tivissa: Ibers a l'Ebre, recerca $i$ interpretació (Tivissa 23-24 de novembre de 2001). Ilercavònia, 3: 17-35.

JunYent, E. (2002b). La quotidianitat a l'època ibèrica. A: Ribes, J. L. (ed.). Sala d'Arqueologia. Catàleg. Quaderns de la Sala d'Arqueologia, 2. Institut d'Estudis Ilerdencs. Lleida: 27-38.

Junyent, E. (2002c). El jaciment ibèric de Gebut (Soses). A: Ribes, J. L. (ed.). Sala d'Arqueologia. Catàleg. Quaderns de la Sala d'Arqueologia, 2. Institut d'Estudis Ilerdencs. Lleida: 39-42.

JunYENT, E. (2002d). La quotidianitat a l'època ibèrica: fitxes tècniques. A: Ribes, J. L. (ed.). Sala d'Arqueologia. 
Catàleg. Quaderns de la Sala d'Arqueologia, 2. Institut d'Estudis Ilerdencs. Lleida: 45 i ss.

Granollers, T., Lorés, J., Raimat, G., Junyent, E., TARTERA, E. (2002a). Vilars. A new dialog model applying Augmented Reality. A: 9th International Workshop: Design, Specification, and Verification of Interactive Systems (DSV-IS 2002) (Rostock, Germany, June 12-14, 2002). Computer Science Preprint Archive, vol. 2002, Issue 7: 282-295. Available at SSRN: <https://ssrn.com/ abstract $=3125378>$.

Granollers, T., Lorés, J., Raimat, G., Junyent, E., TARTERA, E. (2002b). Vilars, un nuevo modelo de diálogo aplicando Realidad Aumentada. A: AEDo, I. DíAz, P., Fernández, C. (eds.). Interacción 2002. III Congreso Interacción Persona Ordenador (Leganés, 8-10 de mayo de 2002). AIPO: 276-279.

Junyent, E., Alberich, J. (2003). Les defenses del campament aqueu a la guerra de Troia. A: Alonso, N., Junyent, E., Lafuente, A., López, J. B. (coords.). Chevaux-de-frise $i$ fortificació en la primera edat del ferro europea. Universitat de Lleida i Consell Comarcal del Segrià. Lleida: 35-67.

\section{G.I.P.:}

Alonso, N., Colet, A., Gené, M., Gómez, X., Junyent, E., Lafuente, A., López, J. B., Moya, A., Tartera, E., VIDAL, A. (2003). Caballos y hierro. El campo frisio y la fortaleza de 'Els Vilars d'Arbeca' (Lleida, España), siglos viII-IV a.n.e. A: Alonso, N., Junyent, E., LAfuente, A., López, J. B. (coords.). Chevaux-de-frise i fortificació en la primera edat del ferro europea. Universitat de Lleida i Consell Comarcal del Segrià. Lleida: 233-274.

Junyent, E., Alonso, N., Colet, A., Gené, M., Lafuente, A., López, J. B., Moya, A., Tartera, E., Vidal, A. (2003). Projecte de recuperació i presentació al públic de la fortalesa d'Arbeca. A: Beltrán de Heredia, J., FernándeZ DEL Moral, I. (coords.). II Congrés Internacional sobre museützació de jaciments arqueològics. Nous conceptes $i$ estratègies de gestió i comunicació (Barcelona, 7-9 octubre 2002). Museu d'Història de la Ciutat. Barcelona: 160-166.

Tartera, E., Junyent, E., Granollers, T., Raimat, G., Lorés, J. (2003). Análisis y diseño de una visita guiada a la Fortaleza de Arbeca en realidad aumentada. A: Beltrán de Heredia, J., Fernández del Moral, I. (coords.). II Congrés Internacional sobre museïtzació de jaciments arqueològics. Nous conceptes $i$ estratègies de gestió i comunicació (Barcelona, 7-9 octubre 2002). Museu d'Història de la Ciutat. Barcelona: 265-269.

G.I.P. i G.R.I.H.O. (2004). Arqueología virtual: la fortaleza ibérica de Arbeca (siglos VIII-IV a.C.). A: Guitart, J., Pera, J. (eds.). Primer Simposi "Patrimoni i Turisme Cultural": Arqueologia viva de les ciutats de l'Antiguitat (Lleida, 4-6 octubre 2001). Institut d'Estudis Catalans-Patronat d'Arqueologia de Guissona. Barcelona: 213-233.

Alonso, N., Colet, A., Escala, O., Gené, M., Junyent, E., Lafuente, A., López, J. B., Moya, A., Tartera, E., Vidal, A. (2005). Dos hogares orientalizantes de la fortaleza de Els Vilars (Arbeca, Lleida): A: Celestino,
S., Jiménez, J. (eds.). El Periodo Orientalizante. Actas del III Simposio Internacional de Arqueología de Mérida: Protohistoria del Mediterráneo Occidental (Mérida 5-8 mayo 2003). Anejos de AEspA, XXXV, vol. I: 651-667.

Alonso, N., Junyent, E., Lafuente, A., López, J. B., Moya, A., Tartera, E., Vidal, A. (2006). Agricultura i poblament a la plana occidental catalana durant l'edat de bronze. A: Bolòs, J., Jarné, A., Vicedo, E. (eds.). Condicions de vida al món rural. Cinquè congrés sobre sistemes agraris, organització social i poder local. Institut d'Estudis Ilerdencs. Lleida: 711-726.

VidAL, A., JunYENT, E. (2007). El patrimonio arqueológico inmueble de la demarcación geoturística "Terres de Lleida": criterios de evaluación y modelos de actuación. A: Varela, P. (coord.). IV Congreso Internacional sobre Musealización de Xacementos Arqueolóxicos: Conservación e Presentación de xacementos arqueolóxicos no medio rural. Impacto social no Territorio. Xunta de Galicia. Dirección Xeral de Patrimonio Cultural. Santiago de Compostela: 323-330.

Vidal, A., Tartera, E., Alonso, N., Aguiló, C., Junyent, E., Lorés, J. (2007). Vilars AR Project. Testing the Augmented Reality Paradigm in an Archaeological Site. A: Figueiredo, A., Leite Velho, G. (eds.). The world is in your eyes. CAA2005. Computer Applications and Quantitative Methods in Archaeology. Proceedings of the 33rd Conference (Tomar, 21-24 March 2005). CAA Portugal. Tomar: 39-43.

Associació d’Amics de Vilars i GIP: Alonso, N., Colet, A., Escala, O., Junyent, E., Lafuente, A., López, J. B., Moya, A., Nieto, A., Tartera, E., Vidal, A. (2007). L'Associació d'Amics de Vilars: Anàlisi i balanç en el seu primer aniversari. A: Alonso, N., Junyent, E., Lafuente, A., López, J. B., Tartera, E., Vidal, A. (eds.). Associacions d'Amics del Patrimoni Arqueològic. Funció $i$ rol social en el segle XXI. Edicions de la Universitat de Lleida. Lleida: 149-171.

Junyent, E. (2008). La vaixella de vernís roig ilergeta. A: Vergès, J. M., López, J. (coords.). II Prehistòria i Història Antiga, Col.lecció: Valls $i$ la seva història, Institut d'Estudis Vallencs, Valls: 212-214.

Nieto, A., Gardeisen, A., Junyent, E., López, J. B. (2010). Inhumations de foetus d'équidés dans la forteresse du premier âge du Fer de Els Vilars (Arbeca, Catalogne). A: Gardeisen, A., Furet, E., Boulbes, N. (eds.). Actes du colloque: Histoire d'équidés, des textes, des images et de os. Actes table ronde (Montpellier 13-14 març 2008). Monographies d'Archéologie Méditerranéenne, Hors-série 4. Association pour le Dévelopement de l'Àrchéologie en Languedoc-Roussillon. Lattes: 125-147.

Poch, R. M ${ }^{\mathrm{a}}$, Balasch, C., Junyent, E. (2010). Micromorphological evidences for ponding regimes and water management of the moat of the Iberian site of Els Vilars (Catalonia). A: LisA, L. (ed.). Abstract book of the International Working Meeting in Archaeological Soil Micromorphology (17th - 21st of May 2010, Brno, Czech Republic). Czech Geological Society. Prague: 29-31. 
Junyent, E. (2012). Reflexionar la rodalia. A: Belarte, M. C., Plana, R. (eds.). El paisatge periurbà a la Mediterrània occidental durant la protohistòria $i$ l'antiguitat a la Mediterrània occidental: actes del col.loqui (Tarragona, 6-8 de maig de 2009). Documenta, 26. Institut Català d'Arqueologia Clàssica. Tarragona: 343-347.

Junyent, E., Casals, C. (2013). La fortalesa dels Vilars d'Arbeca. Conservació i socialització. A: Fortificaciones. Intervenciones en el patrimonio defensivo. Actas del XXXIV Curset. Jornadas Internacionales sobre la intervención en el Patrimonio Arquitectónico (Barcelona y Tortosa, 15-18 diciembre de 2011). Ministerio de Educacion, Cultura y Deporte - Col-legi Oficial d'Arquitectes de Catalunya. Madrid: 49-58.

Junyent, E. (2014a). Història de la descoberta de la fortalesa dels Vilars d'Arbeca. La fortalesa dels Vilars d'Arbeca, passat i present. A: SANS, J. M ${ }^{\mathrm{a}}$, PAU, A., JunYent, E. Arbeca. història $i$ record, 30 anys després. Ajuntament de la Vila d'Arbeca. Mollerussa: 212-245.

Junyent, E. (2014b). La Fortalesa dels vilars d'Arbeca. A: Molist, M., RodÀ, I., Pladevall, A. (dirs.). Patrimoni Monumental de Catalunya, vol. 1, De la Prehistòria a l'Edat Mitjana. Enciclopèdia Catalana, SA. Barcelona: 38-39.

JunYent, E. (2015a). L'evidència arqueològica en la definició de la societat estatal arcaica ilergeta. A: Belarte, M. C., García, D., Sanmartí, J. (eds.). Actes de la VII Reunió Internacional d'Arqueologia de Calafell: Les estructures socials a la Gàl-lia i a Ibèria. Homenatge a Aurora Martín i Enriqueta Pons (Calafell, 7-9 març 2013). Arqueomediterrània, 14: 165-191.

Junyent, E. (2015b). Reflexions sobre criteris arquitectònics d'intervenció en jaciments arqueològics. Els casos del Dolmen de Reguers (Seró-Artesa de Segre) i de la Fortalesa dels Vilars (Arbeca). A: Company, X., Puig, I., Montgay, C., Machetti, S. (eds.). El gran valor de les lletres i les humanitats. Homenatge al Dr. Frederic Vilà $i$ Tornos. Edicions i publicacions de la Universitat de Lleida. Lleida: 147-154.

Nieto, A., López, J. B., Junyent, E. (2016). Nuevos datos sobre la presencia del caballo en las comunidades protohistóricas del Valle del Segre. A: Coimbra, F. A. (coord.). The Horse and the Bull in Prehistory and History. Cordero Editore. Génova: 117-134.

Junyent, E. (2017). El cas de La Higiènica (1980-1981): universitat, ciutat i llibertat d'expressió. A: PonT, J., SANTA, A. (eds.). Universitat i ciutat. Tot recordant Víctor Siurana (1945-1993). Pagès editors. Lleida: 231-265.

Junyent, E. (2018). 775-300 aC. Terra, aigua i poder en el món iber. A: DE Riquer, B. (dir.). Història Mundial de Catalunya. Edicions 62. Barcelona: 56-65.

Alonso, N., Bernal, J., Castellano, A., Gonzàlez, S., Junyent, E., López, J. B., Martínez, J., Mazuque, J., Nieto, A., Oliva, J. A., Piquès, G., Prats, G., Vila, S. (2018). La fortalesa dels Vilars (Arbeca, les Garrigues): Noves aportacions sobre la primera edat del ferro i l'època ibèrica (2010-2015). A: Primeres Jornades d'Arqueologia $i$ Paleontologia de Ponent (Balaguer $i$ Lleida, 17-18 d'abril de 2015). Generalitat de Catalunya. Departament de Cultura. Barcelona: 88-99.

\section{Llibres}

Junyent, E., Valldellou, V. (1972d). Una vivienda ibérica de Mas Boscá. Publicaciones Eventuales, 21. Instituto de Arqueología y Prehistoria. Universitat de Barcelona. Barcelona.

Junyent E., Pérez, A. (1983). El Museu de la Paeria. Servei de Publicacions de la Paeria de Lleida. Lleida.

Gallart, J., Junyent, E., Pérez, A., Rafel, N. (1985). L'arqueologia a la ciutat de Lleida 1975-1985. Col-lecció "La Banqueta. Quaderns de divulgació ciutadana”, 5. Ajuntament de Lleida. Lleida.

GALLART, J., JunYENT, E. (1989). Un nou tall estratigràfic a La Pedrera, Vallfogona de Balaguer-Termens, La Noguera, Lleida. Espai/Temps. Quaderns del Departament de Geografia i Història de l'Estudi General de Lleida, 3. Lleida.

JunYent, E. (dir.) (1996). Els temps prehistòrics $i$ antics. Fins al segle $v$. A: de Riouer, B. (dir.). Història, Politica, Societat i Cultura als Països Catalans. Vol. I. Enciclopèdia Catalana S. A. Barcelona.

Garcés, I., Junyent, E., Lafuente, A., López, J. B. (1997). Vilars 2000. Una fortalesa ilergeta d'ara fa 2.700 anys. Universitat de Lleida. Lleida.

Alonso, N., Gené, M., Junyent, E., Lafuente, A., López, J. B., Moya, A., TARTERA, E. (coords.) (2002). Recuperant el passat a la línia del Tren d'Alta Velocitat. L'assentament protohistòric, medieval i d'època moderna de El Vilot de Montagut (Alcarràs, Lleida). Pagès Editors. Lleida.

Junyent, E., Pérez, A. (2003). Història de Lleida. L'antiguitat, d'Iltirta a Ilerda, vol. 1. Pagès Editors. Lleida.

Alonso, N., Junyent, E., Lafuente, A., López, J. B. (coords.) (2003). Chevaux-de-frise $i$ fortificació en la primera edat del ferro europea. Universitat de Lleida i Consell Comarcal del Segrià. Lleida.

Alonso, N., Junyent, E., Lafuente, A., López, J. B. (2005). Arbeca. La Fortalesa dels Vilars. Guies del Museu d'Arqueologia de Catalunya. Generalitat de Catalunya. Barcelona.

Alonso, N., Junyent, E., Lafuente, A., López, J. B., TARTERA, E., Vidal, A. (eds.) (2007). Associacions d'Amics del Patrimoni Arqueològic. Funció $i$ rol social en el segle XXI. Edicions de la Universitat de Lleida. Lleida.

Alonso, N., Junyent, E., López, J. B. (2010). Arbeca. La Fortalesa dels Vilars. Guies del Museu d'Arqueologia de Catalunya. Generalitat de Catalunya. Barcelona. 
Junyent, E., Poch, R. Ma, Balasch, C. (2012). The Iberian Fortress of Els Vilars. Mid-Meeting Excursion Guide - 14th International Working Meeting on Soil Micromorphology (Lleida, 8-14 juliol de 2012). Edicions Universitat de Lleida. Lleida.

SAns, J. M ${ }^{\mathrm{a}}$, Pau, A., Junyent, E. (2014). Arbeca. història $i$ record, 30 anys després. Ajuntament de la Vila d'Arbeca. Mollerussa.

Junyent, E., López, J. B. (2016). La fortalesa dels Vilars d'Arbeca. Terra, aigua $i$ poder en el món iber. The Vilars d'Arbeca Fortress. Land, Water and Power in the Iberian World. Museu de Lleida. Lleida.

\section{Publicacions multimèdia}

GP I GRIHO: Junyent, E., LoRÉs, J. (coords.) (1998). CD-ROM: Vilars 2000. Vilars Virtual. Una fortalesa ilergeta d'ara fa 2700 anys. Dragoli Produccions. Universitat de Lleida.
GIP: Alonso, N., López, J. B., Junyent, E., Lafuente, A. (coords.) (1998). <http://www.vilars2000.com>.

GIP (2000). <http://www.mcu.es/igc/Jornadas/ Eupa_2000/Els_vilars.html>.

GP I GRIHO (2001). Vídeo: La fortalesa ibèrica d'Arbeca, segles VIII i vII a.n.e. DL: LL-637-2001

GP I GRIHO (2005). CD-ROM: La fortalesa ibèrica d'Arbeca, segles vIII i vII a.n.e. Edicions de la Universitat de Lleida. Lleida.

Junyent, E. (2010). CD-ROM: Fortalesa ibèrica dels Vilars, bronze final-ferro ibèric ple. Arbeca (Garrigues). A: IP 30: trenta anys d'intervencions en el patrimoni a les terres de Lleida, 1980-2010. Generalitat de Catalunya. Departament de Cultura i Mitjans de Comunicació. Barcelona.

GIP (2012): <http://www.vilars.cat> (Lavert). 